\title{
Review
}

\section{Melatonin, hormone of darkness and more - occurrence, control mechanisms, actions and bioactive metabolites}

\author{
R. Hardeland \\ Johann Friedrich Blumenbach Institute of Zoology and Anthropology, University of Göttingen, Berliner Str. 28, \\ 37073 Göttingen (Germany), Fax: +49551395438, e-mail: rhardel@gwdg.de
}

Received 2 January; received after revision 6 February 2008; accepted 8 February 2008

Online First 17 March 2008

\begin{abstract}
In its role as a pineal hormone, melatonin is a pleiotropic, nocturnally peaking and systemically acting chronobiotic. These effects are largely explained by actions via $G$ protein-coupled membrane receptors found in the suprachiasmatic nucleus, but also in numerous other sites. Nuclear (ROR/RZR), cytoplasmic (quinone reductase-2, calmodulin, calreticulin) and mitochondrial binding sites and radicalscavenging properties contribute to the actions of melatonin. Regulation of pineal melatonin biosynthesis is largely explained by control mechanisms acting on arylalkylamine $\mathrm{N}$-acetyltransferase, at the
\end{abstract}

levels of gene expression and/or enzyme stability influenced by phosphorylation and interaction with 14-3-3 proteins. Melatonin is not only a hormone but is also synthesized in numerous extrapineal sites, in which it sometimes attains much higher quantities than in the pineal and the circulation. It is also present in many taxonomically distant groups of organisms, including bacteria, fungi, and plants. Moreover, melatonin is a source of bioactive metabolites, such as 5methoxytryptamine, $N^{1}$-acetyl- $N^{2}$-formyl-5-methoxykynuramine and $N^{1}$-acetyl-5-methoxykynuramine.

Keywords. AFMK, AMK, cinnoline, indoleamine, melatonin-binding site, 5-methoxytryptamine, nitric oxide, pineal gland.

\section{Introduction}

Melatonin was discovered as a pineal hormone, which lightens skin of fish and amphibia by concentrating mobile melanosomes of melanocytes (melanophores) involved in physiological color change [1]. Even this frequently cited observation from a pioneering work is not without exception. In pencil fish, melanocytes showed area-specific melanosome concentration or dispersion [2]. Therefore, melatonin is not just another example of the various skin-lightening hormones present in several animal taxa, but rather transmits signals eliciting different site-specific responses. This view was confirmed by the discovery of high-amplitude circadian melatonin rhythms in the pineal gland and the circulation with prominent nocturnal peaks, which were suppressed by light [3-7]. The chronobiological roles of melatonin as a mediator of dark signals regulating both circadian oscillators and seasonality have been reviewed many times and would exceed the frame of this article.

Meanwhile, melatonin has turned out to be a ubiquitous compound, detected in all major taxa studied so far, including bacteria, dinoflagellates and other eukaryotic protists, macroalgae, plants, fungi, and various groups of invertebrate animals [for details see refs 8-10]. In brief, the following lessons can be deduced from these findings: (i) melatonin is not generally associated with darkness, but can sometimes also be elevated during photophase; (ii) in some 
species, it may even be arrhythmic; (iii) where it is found to exhibit circadian oscillations, these are not necessarily implicated in seasonality; (iv) in plants, morphogenetic and photoprotective actions may be of importance; (v) the concentrations of non-vertebrate melatonin can vary extremely between species or taxa and sometimes attain values in the upper micromolar range. Therefore, melatonin can no longer be seen solely as a trace compound, nor generally as a hormone, and its functions have to be highly divergent in the various organisms.

Although this indoleamine has been perceived for decades in a mainly chronobiological context, even vertebrate melatonin is not exclusively a hormone present in only minute quantities and acting via the $\mathrm{G}$ protein-coupled membrane receptors $\mathrm{MT}_{1}$ and $\mathrm{MT}_{2}$. High-amplitude circadian oscillations, which mediate the signal darkness, are not generally found. Tissue melatonin enters the circulation poorly is and thus only partially removed by hepatic first-pass metabolism and not quantitatively excreted as 6-sulfatoxymelatonin. Therefore, the role as a mediator of the signal darkness only reflects a part of the wider spectrum of actions, presence, dynamics and metabolism exhibited by this remarkably pleiotropic and ubiquitous indoleamine. This review will deal with both the considerable progress made in understanding the cell biology of the classic functions of melatonin and its roles beyond them.

\section{Extrapineal melatonin: remarkable quantities and non-classic roles}

Extrapineal melatonin is somehow reminiscent of cosmological dark matter. There is by far more melatonin outside than inside the pineal gland and circulation, but its extrapineal functions are poorly understood, whereas the hormone secreted by the pineal gland and its transmission of dark signals is part of general knowledge and awareness. The much higher quantities of extrapineal melatonin are frequently not perceived by researchers or are considered irrelevant. However, extrapineal melatonin will substantially widen our understanding of the numerous roles of this molecule.

Pineal melatonin is formed from serotonin by two steps catalyzed by arylalkylamine $N$-acetyltransferase (AA-NAT) and hydroxyindole $O$-methyltransferase (HIOMT) [6, 7]. In extrapineal sites and outside vertebrates, other enzymes can be involved and regulation mechanisms may be different. Extrapineal melatonin synthesis has been identified, e,g. in the retina [11-13], the Harderian gland [14-16] and later in the parietal organ of reptiles [17]. At first glance, retina and parietal organ, also being extrusions of the intermediate brain, may appear as variants of the same theme known from the pineal gland. They can likewise generate robust, nocturnally peaking circadian rhythms. However, with the exception of amphibian and some avian retinas, melatonin is only poorly released from these organs. Consequently, melatonin serves additional functions and is not only acting as a hormone. Retinal melatonin efficiently downregulates dopamine formation and release [11, 13]. Despite the similar rhythmicities of pineal and retinal melatonin, their regulation can be entirely different. While melatonin in the mammalian pineal is largely regulated by norepinephrine of sympathetic origin, retinal melatonin biosynthesis is stimulated via $\mathrm{GABA}_{\mathrm{A}}$ and, partially, GABA $\mathrm{B}_{\mathrm{B}}$ receptors [13]. The light-dependent decrease of retinal melatonin is caused by dopamine via $\mathrm{D}_{1}$ or $\mathrm{D}_{4}$ receptors [18]. Differences in metabolism exist, too, because retinal melatonin is largely degraded by deacetylation to 5methoxytryptamine (5-MT) [12, 19], a compound which can be further converted to 5-methoxytryptophol (5-ML) or 5-methoxyindoleacetic acid (5MIAA) $[8,10,20]$. In the retina, deacetylation to 5MT can be catalyzed by a specific melatonin deacetylase, but in other organs or organisms by less specific aryl acylamidases (AAAs) or eserine-sensitive acetylcholinesterase [20]. 5-MT is a bioactive compound too $[8,10,20]$ and may play a role of its own in the retina. In cultured retinal cells, it reportedly prevented the forskolin-induced rise in cyclic AMP, independently of the melatonin receptors [21]. Where not released from an organ, melatonin cannot not be degraded in the liver or appear as urinary 6-sulfatoxymelatonin. In the brain, substituted kynuramines were identified as major metabolites [22].

While robust circadian rhythmicity is typical for pineal, parietal and retina, this is not so with the rodent Harderian gland. Diurnal changes are poorly expressed or almost absent, except for a transient drop after onset of light $[14,16]$. Therefore, melatonin is not always associated with darkness in vertebrates. Variations of Harderian melatonin were observed within sexual or seasonal cycles, but these are related to changes in gonadosteroids $[14,23]$. Thus, annual fluctuations appear as a consequence rather than a cause of reproductive cycles.

Melatonin biosynthesis has been reported, or assumed, for various additional tissues and cells, and, in most cases, a transmission of dark signals seems highly unlikely or impossible. Circadian rhythms, if present, frequently exhibit small amplitudes or are at the borderline of detection. In the mammalian brain, other sites of melatonin formation may exist, although the evidence is relatively weak to date, whereas more 
information exists on the synthesis of the precursor, $\mathrm{N}$ acetylserotonin (NAS). $O$-methylation of NAS is not necessarily an action of HIOMT, as in pineal, retina and Harderian gland, but can be alternately catalyzed by less specific methyltransferases. Relatively high concentrations (up to $0.7 \mu \mathrm{M}$ ) of melatonin in the brain have been reported [24], a finding which would be in favor of local melatonin synthesis in some areas. Abundance and sites of formation of 5-hydroxylated and 5-methoxylated indoles in the central nervous system have been recently summarized [20].

Gastrointestinal melatonin has been reviewed several times [e.g., 25-27]. The indoleamine is produced in enterochromaffin cells, but circulating melatonin can be additionally taken up from the blood. Although concentrations remain moderate, the entire gastrointestinal tract contains, owing to its size, about 400500 times more melatonin than the pineal gland [26, 27]. Its fate is complex, because the gut acts both as source and sink. Uptake of circulating melatonin has been studied by elevating its plasma level during daytime to nighttime values [28]. Substantial amounts were subsequently found unmetabolized in the intestinal lumen [28]. This is in good agreement with high quantities of melatonin in the bile fluid [29] and enterohepatic cycling $[29,30]$. Additionally, melatonin is taken up from food. Diurnal plasma levels were increased by natural diets rich in melatonin, or decreased by melatonin-depleted food [27, 31]. A contribution of intestinal bacteria to melatonin in the gut seems possible, but requires further investigation [9]. Gastrointestinal melatonin can be released to the circulation, in terms of a post-prandial response [26, 27], in particular, by elevated tryptophan [32]. Melatonin surges elicited by this amino acid are considerable in height, but of relatively short duration. During daytime, they remain chronobiologically almost ineffective, since they appear in the silent zone of the circadian phase-response curve [27]. Gastrointestinal melatonin can also exhibit a circadian rhythmicity of relatively low amplitude (maximum/minimum $\leq 2: 1$ ) [27], which is sometimes barely detectable [26, 27].

Mammalian skin has been reported to be another site of melatonin biosynthesis. The formation and presence of the enzymes required have been demonstrated [33]. Serotonin $N$-acetylation is catalyzed by either AA-NAT or by an arylamine $N$-acetyltransferase subform [34]. An important and obviously unsettled point concerns melatonin levels in vivo. Earlier attempts to quantify this indoleamine in skin samples by liquid chromatography failed to demonstrate melatonin, and HIOMT activity remained below detection levels [35], contrary to cultured $\mathrm{HaCaT}$ keratinocytes, which contained very high amounts (ca
$30 \mu \mathrm{M}$ melatonin, under consideration of an erratum) [36]. A clarification of this discrepancy is urgently required, to decide between dysregulation in cultured, immortalized cells and inefficiency of safe extraction from biopsies, as caused by oxidants in biological material $[9,20]$.

Melatonin formation has been reported for several other vertebrate tissues and cells, such as bone marrow [37] - along with assumptions concerning hematopoietic activity of melatonin [38] - and various types of leukocytes $[39,40]$, platelets, erythrocytes and the membranous cochlea [summarized in ref. 39]. Elevated concentrations in other tissues [40,41] may be explained by uptake from the circulation. In some cases, melatonin formation may result from inevitable side reactions by unspecific $N$-acetyl and $O$-methyltransferases, e.g., in erythrocytes.

\section{Regulation of melatonin biosynthesis}

The classic pathway of melatonin formation involves four steps, starting with tryptophan 5-hydroxylase, followed by 5-hydroxytryptophan decarboxylation by aromatic amino acid decarboxylase, $\mathrm{N}$-acetylation of serotonin by AA-NAT, and $O$-methylation of NAS by HIOMT. Alternately, homologs or structurally different $N$-acetyl- and $O$-methyltransferases can be involved. In principle, the steps could also take place in different sequential orders, e.g., serotonin $\rightarrow 5$ MT $\rightarrow$ melatonin, or 5-hydroxytryptophan $\rightarrow 5$-methoxytryptophan $\rightarrow 5$-MT $\rightarrow$ melatonin, but, in all cases studied so far, the alternate sequences were of minor importance. In organs or organisms which deacetylate melatonin [42], re-acetylation of 5-MT may be of some relevance [10]. In the classic pathway, AA-NAT is usually believed to be the rate-limiting enzyme, although tryptophan 5-hydroxylase can represent an additional control step, e.g., in amphibia. Exceptions to this rule have been described. In Drosophila, NAS concentrations are three orders of magnitude higher than those of melatonin [43], and thus $O$-methylation is limiting, a finding explained by the loss of the HIOMT gene, so that methyl transfer has to be catalyzed by other, presumably less specific enzymes [20]. A functionally similar situation seems to be present in the retinas of primates and ungulates, in which HIOMT is not or poorly expressed at both mRNA and protein levels [7]. Whether this leads to a complete lack of retinally derived melatonin or only to a reduction, remains to be clarified. In other mammalian taxa, such as rodents, and in non-mammalian vertebrates, HIOMT is sufficiently expressed in the retina, and melatonin exhibits a nocturnally peaking circadian rhythm. However, the rate limitation by 
AA-NAT was also disputed for the nocturnal rise of melatonin in the rat pineal [44]. Because of nocturnal NAS concentrations exceeding those of melatonin and findings in a low-activity AA-NAT mutant $(\mathrm{H} 28 \mathrm{Y})$, these investigators concluded that HIOMT becomes rate-limiting at night.

The premier significance of AA-NAT - recently called 'the timezyme' [7] - as the rate-limiting enzyme of melatonin biosynthesis, e.g., in pinealocytes, deserves an outline of its regulation. AA-NAT can be regulated at different levels, that of gene expression and that of enzyme activation and stability (Fig. 1). Which of these mechanisms is responsible in a specific case, or even both of them, depends on species and organ. Two different types of control have to be distinguished, which can complement each other under natural conditions: (i) a circadian regulation, either via components of the oscillator or by norepinephrinedependent rhythms of protein kinases, and (ii) a photic turnoff mechanism. Transcriptional regulation is afforded by respective control elements in the AA-NAT promoter, especially photoreceptor conserved elements (PCEs; RCS in Drosophila) [45, 46], which respond to transcription factors of the CRX/OTX family [46, 47], and E-boxes, which can be under direct control of an oscillator, e.g. by binding of BMAL1/ CLOCK or, in humans, BMAL1/MOP4 heterodimers [7, 48]. E-boxes can also be accessible to other transcription factors or modulated by additional control elements [48]. In mammalian pineals, calcium/cAMP response elements (CREs) can be involved in sympathetic stimulation [7, 49-51].

Regulation at the level of the translated enzyme protein comprises phosphorylation and interaction of the phosphorylated AA-NAT with a 14-3-3 protein (isoforms $\xi$ or $\varepsilon$ ). Both cAMP and $\mathrm{Ca}^{2+}$ signaling can contribute to this mechanism, involving either protein kinase A (PKA) $[7,51,52]$ or protein kinase $\mathrm{C}$ (PKC) [53]. Phosphorylation depends on N- and C-terminal flanking regions, which are typical for the vertebrate AA-NAT, but not found in homologs or paralogs of urochordates, invertebrate animals or other organims [7]. These regions contain PKA- and PKC-specific motifs. The association of AA-NAT with a 14-3-3 protein (usually studied with subform $\zeta$ ) results in stabilization of the enzyme protein [7, 52]. Scaffolding with 14-3-3 protein may also favor the stability of the enzyme's active center [7]. The stoichiometry of the complex (one or two AA-NAT molecules with one 14$3-3 \zeta$ dimer) is still uncertain. It is of particular functional significance that the stability of the complex remains moderate, so that it regularly dissociates and AA-NAT becomes accessible to protein phosphatases [52]. The dephosphorylated enzyme is prone to rapid proteasomal degradation $[7,54]$. The velocity of this process can explain a rapid enzyme inactivation observed upon exposure to nocturnal light, a major component of the photic turnoff mechanism, which may, however, be accompanied by a shutoff at the level of gene transcription.

The two mechanisms of regulation, which act on either gene expression or enzyme stability, are effective to a different extent among species, and additional variations become apparent between melatonin-synthesizing organs. The AA-NAT phosphorylation/14-3-3 mechanism is present in all vertebrates, at least in the pineal gland, whereas this cannot be the case in non-vertebrate organisms which lack the $\mathrm{N}$ - and $\mathrm{C}$ terminal flanking regions [7]. Other post-translational modifications and interactions with different proteins that may shield modified amino acid residues have not been studied outside the vertebrates. Data on transcriptional control of non-vertebrate AA-NAT homologs or paralogs are largely missing (except of processes related to cuticle formation), and the wide distribution of $\mathrm{N}$-acetyltransferases indicates other functions not related to melatonin, but, e.g., to sclerotization. Even within the mammals, fundamental differences exist, so that findings obtained in rodents are not generally applicable to humans. In the pineal gland of primates and ungulates, AA-NAT seems to be only regulated by formation and decay of the phospho-AA-NAT/14-3-3 complex [7], as far as is known. This is sufficient for a considerable nocturnal rise in active enzyme protein as well as the photic shutoff taking place as soon as cAMP decreases and, consequently, PKA activity. In rhesus monkeys, a 4fold nocturnal increase in AA-NAT activity was observed, whereas its mRNA did not show substantial variations [7]. Similar findings were made in sheep and cattle [7, 54]. However, rodents exhibit a rhythm in pineal AA-NAT mRNA of remarkable amplitude, with 100- or even 150-fold nocturnal rises [7, 49, 55, 56].

The rhythm of AA-NAT mRNA as well as an additional shutoff mechanism at the expression level have turned out to be multifaceted phenomena, which do not seem to be solely explained by the rate of transcription, although this is, of course, an important basis. Transcription is, again, subject to both positive and negative control. Expression can be regulated either directly by a circadian oscillator, via transcription factors mentioned above, or indirectly via a neuronal pathway which is typical for mammals, but contributes to a certain extent also to the pineal rhythm in birds. In the directly light-sensitive pineal glands of non-mammalian species and in retinal photoreceptors, an autonomous, primary circadian oscillator is present in AA-NAT-expressing cells [7, $57,58]$, so that this enzyme can be under direct control 


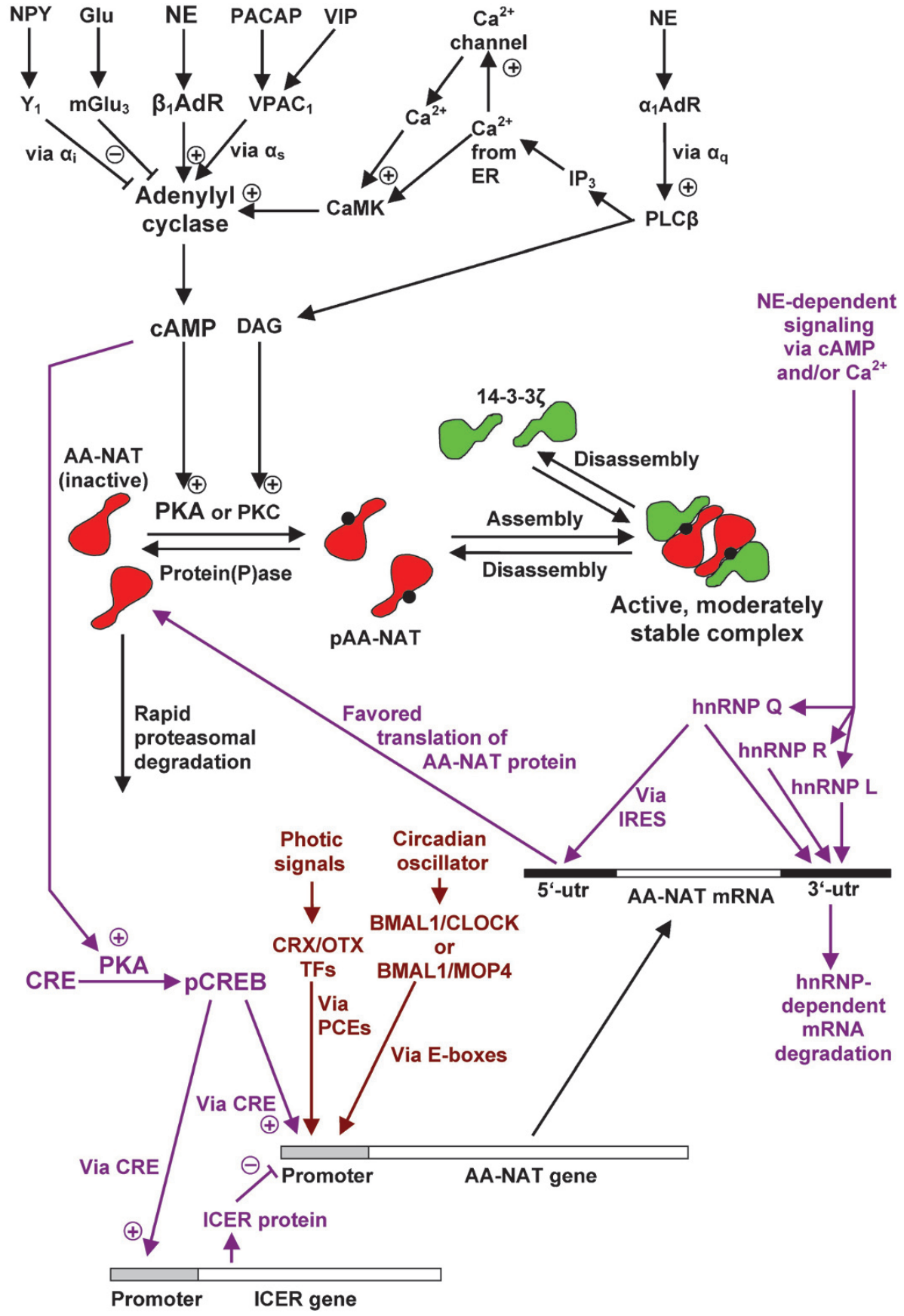

Figure 1. Regulation of AANAT expression and activity. The scheme combines different pathways which are not collectively present in any one system. Black arrows and lettering: pathways present in pineal glands of many mammals; violet color: pathways present in rodents, but not (or not demonstrated) in primates and ungulates; brown color: pathways present in systems containing endogenous, self-sustained oscillators (nonmammalian systems and some mammalian retinas). Pathways of particular importance are emphasized by larger letters. AANAT, arylalkylamine $N$-acetyltransferase; $\alpha_{\mathrm{i}}, \alpha_{\mathrm{s}}, \alpha_{\mathrm{q}}, \alpha$ subunits of respective $\mathrm{G}$ proteins; $\alpha_{1} \mathrm{AdR}$, $\alpha_{1}$-adrenergic receptor; $\beta_{1} \mathrm{AdR}$, $\beta_{1}$-adrenergic receptor; CaMK, calcium/calmodulin-dependent kinase; CRE, calcium/cAMP response element; CREB, CREbinding protein; Glu, glutamate; hnRNP, heterogeneous nuclear ribonucleoprotein; ICER, inducible cAMP early repressor; IRES, internal ribosome entry site; $\mathrm{mGlu}_{3}$, metabotropic glutamate receptor type 3; NE, norepinephrine; NPY, neuropeptide Y; PACAP, pituitary adenylyl cyclase activating peptide; PCE, photoreceptor conserved element; PKA, protein kinase A; PKC, protein kinase C; PLC $\beta$, phospholipase $\mathrm{C} \beta$; TFs, transcription factors; utr, untranslated sequence; VIP, vasoactive intestinal polypeptide; $\mathrm{VPAC}_{1}$, VIP/PACAP receptor-1; $\mathrm{Y}_{1}$, NPY receptor-1. of the oscillator. In addition to transcription factors that are part of the clockwork, the oscillator can also regulate AA-NAT expression by modulating cAMP levels, as shown for avian retinas $[57,58]$.

The mammalian pineal gland is controlled by the suprachiasmatic nucleus (SCN), a hypothalamic structure acting as a circadian master clock. The photic input is mediated via the retinohypothalamic tract, the paraventricular nucleus and a sympathetic connection from the intermediolateral cell column of the upper thoracic cord to the superior cervical ganglion, which innervates the pineal [59]. Norepinephrine released from the post-ganglionic sympathetic fibers acts via two signaling pathways, which complement and reinforce each other. Binding to $\beta_{1}$-adrenergic receptors leads to activation of adenylyl cyclase and, consequently, PKA [7, 51, 55], whereas a concomitant action via $\alpha_{1 \mathrm{~B}}$-adrenergic receptors causes, via $G_{0}$ and phospholipase $\mathrm{C} \beta$, a rise in $\mathrm{Ca}^{2+}{ }_{\text {ii }}$, membrane translocation and activation of PKC [51, 53]. Moreover, elevated cAMP and $\mathrm{Ca}^{2+}{ }_{[i]}$ are thought to open $\mathrm{Ca}^{2+}$ channels - although pineal L-channels were shown to 
be shut by cAMP or adrenergic stimulation [60] - and to further stimulate cAMP production via activated CaM kinase [51], which can be additionally upregulated via $\alpha_{1 \mathrm{~B}^{-}}$-adrenergic signaling. Both $\beta_{1^{-}}$and $\alpha_{1 \mathrm{~B}^{-}}$ adrenergic effects jointly regulate the phosphorylation of AA-NAT and, thus, the stabilization by 14-33ร. In systems with transcriptional control, they also stimulate AA-NAT expression by phosphorylation of CREB $\left(\mathrm{Ca}^{2+} / \mathrm{cAMP}\right.$ response element-binding protein), in particular, via PKA type II [7, 51, 61].

The adrenergic cAMP/ $\mathrm{Ca}^{2+}$ regulatory system is further modulated by several neuropeptides and glutamate. Pituitary adenylyl cyclase-activating peptide (PACAP), originating from a trigeminal innervation, and vasoactive intestinal peptide (VIP), from a pterygopalatine connection, stimulate adenylyl cyclase via a common $\mathrm{VPAC}_{1}$ receptor $[51,60]$. Inhibitory actions are mediated by neuropeptide Y (NPY) from both sympathetic nerve endings and the intergeniculate leaflet, via $G_{i}$-coupled pinealocyte $Y_{1}$ and presynaptic $\mathrm{Y}_{2}$ receptors, and from intrapineal glutamate via the metabotropic receptor $\mathrm{mGlu}_{3}$ [51].

Transcription of the Aa-nat gene, as induced by phospho-CREB (pCREB), is subject to two kinds of inhibition. The first represents a negative feedback mechanism. pCREB also induces a truncated CREM (CRE modulator) variant, ICER (inducible cAMP early repressor), which interferes with pCREB binding to its response element $[51,55,61]$. Through this mechanism, Aa-nat expression becomes temporally limited. The other type of inhibition seems to be specific for the photophase when pineal melatonin has to be suppressed. The transcription factors DREAM [downstream regulatory element (DRE) antagonist modulator] and the related KChIP (potassium channel-interacting protein) are capable of downregulating the expression of genes containing DRE in their promoter, in particular Aa-nat, but also Icer [51, 62]. AA-NAT expression is not only controlled at the transcriptional level, but in addition post-transcriptionally by heterogeneous nuclear ribonucleoproteins, hnRNPs R, Q and L. The effects of these proteins are dual, depending on their binding sites. When binding to loops in the $3^{\prime}$-untranslated region ( $\left.3^{\prime} \mathrm{UTR}\right)$ region of the rat AA-NAT mRNA, all three of them strongly favor mRNA degradation [56]. However binding of hnRNP Q to the IRES motif (internal ribosome entry site) in the 5'UTR region stimulates the rate of translation [63]. In rat pineals, all three hnRNPs exhibited robust circadian rhythms [56]. Levels of hnRNP R and Q were shown to peak (maximum/ minimum ratio ca 2 ) around the maximum of $\mathrm{pCREB}$ [zeitgeber time (ZT) 19], about $2 \mathrm{~h}$ after the maximum of AA-NAT mRNA (ZT 17), whereas hnRNP L expression was maximal $4 \mathrm{~h}$ later (ZT 21), with a maximum/minimum ratio of 7 [56]. This indicates a control of AA-NAT mRNA degradation especially by hnRNP L. However, the physiological meaning of the IRES-dependent translational upregulation by hnRNP Q, which contrasts with the negative effect on mRNA stability, requires further elucidation.

\section{Melatoninergic actions via membrane receptors}

Since the pioneering work by S. M. Reppert and colleagues, who first cloned a melatonin receptor from Xenopus melanocytes [64] and who found homologs in other vertebrate species [65-67], high-affinity membrane receptors have been studied in detail. In mammals, two receptors are present, $\mathrm{MT}_{1}$ and $\mathrm{MT}_{2}$ (in earlier terminology called $\mathrm{Mel}_{1 \mathrm{a}}$ and $\mathrm{Mel}_{1 \mathrm{~b}}$ ) [66-68]. The original terminology is sometimes maintained in studies on non-mammalian vertebrates or in comparative work, because a third melatonin receptor type is present in these organisms [69], $\mathrm{Mel}_{1 \mathrm{c}}$, to which no denomination corresponding to $\mathrm{MT}_{1}$ or $\mathrm{MT}_{2}$ is allowed, for formal reasons of nomenclature. Functionally different isoforms of $\mathrm{Mel}_{1 \mathrm{c}}$ have been described, which lead to decreases in cyclic GMP [70]. Mel $_{1 \mathrm{c}}$ must not to be confused with a binding site formerly called $\mathrm{MT}_{3}$, which is an entirely different protein and not a receptor in the strict sense.

As far as can be judged to date, all chronobiotic effects, i.e. all actions directly influencing a circadian master clock, are mediated by the membrane receptors mentioned, in mammals by $\mathrm{MT}_{1}$ and $\mathrm{MT}_{2}$ [6769]. In the SCN, melatonin affects, under both in vivo and in vitro conditions, the phase as well as the amplitude of the circadian oscillation. Phase shifting is preferentially exerted via $\mathrm{MT}_{2}$, whereas neuronal firing is acutely suppressed through $\mathrm{MT}_{1}[67,71,72]$. The two receptor subtypes are complementary in their actions and can, to a limited extent, mutually substitute for each other. This seems important insofar as, exceptionally, a functionally active $\mathrm{MT}_{2}\left(\mathrm{Mel}_{1 \mathrm{~b}}\right)$ receptor can be missing, as found in Siberian hamsters, Phodopus sungorus and P. campbelli [73]. Since the mammalian pineal gland is under control of the SCN, the action of melatonin on this circadian pacemaker represents a feedback mechanism involved in the readjustment of the oscillator.

In seasonal breeders, high densities of the membranebound receptors are also found in the median eminence and pars tuberalis. While many earlier reports deal with binding of $2-\left[{ }^{125} \mathrm{I}\right]$ iodomelatonin, specific $\mathrm{MT}_{1}$ expression was demonstrated in various species, whereas the evidence for the presence of $\mathrm{MT}_{2}$ is mostly indirect, based on immortalized cell lines or antagonist experiments [68,74-76]. Melatonin re- 
ceptors in the median eminence/pituitary system play a pivotal role in seasonal control, especially of sexual activity $[65,68,75,76]$. This includes an influence of daytime information by regulation of clock genes in the pars tuberalis [75]. While melatonin regulates the secretion of hypothalamic and adenohypophyseal hormones, melatonin receptor expression can also be subject to control by gonadotrophin-releasing hormone, at least in a developmental context. Depending on vertebrate taxa or species, the effects of melatonin on reproductive functions are, sometimes, much more complex and involve actions at various levels of the hormonal axis, including the gonads [68]. While $\mathrm{MT}_{1}$ and $\mathrm{MT}_{2}$, or - in birds - $\mathrm{Mel}_{1 \mathrm{c}}$, are highly expressed in the SCN or in the median eminence/ anterior pituitary system, they are also found sometimes in a species-specific manner - in various other tissues, where they can exert numerous effects, which may be chronobiological in nature, owing to the cyclicity of circulating melatonin, but not necessarily chronobiotic, to the extent that master clocks are not involved. The receptors have been detected in many tissues, such as retina, other brain areas, choroid plexus, cerebral and peripheral vasculature, Harderian gland, reproductive organs including myometrium and adrenal cortex [68,76]. Although expression levels remained low in some of these tissues, their ample distribution indicates melatonin responsiveness of numerous peripheral organs [76].

The - demonstrated or assumed - functional significance of melatonin signaling via membrane receptors cannot be outlined here in any detail for all these organs. Instead, with a few selected cases in focus, signal transduction pathways will be discussed. $\mathrm{MT}_{1}$, $\mathrm{MT}_{2}$ and likewise $\mathrm{Mel}_{1 \mathrm{c}}$, are $\mathrm{G}$ protein-coupled receptors $[64-66,68]$. Their classic mode of action is that of a $\mathrm{G}_{\mathrm{i}}$-mediated inhibition of adenylyl cyclase, resulting in decreases of PKA activity and CREB phosphorylation. This holds undoubtedly for SCN neurons, but is, even there, not an exclusive mechanism. As with many other G protein-coupled receptors, the presence of $G$ protein subforms in a particular cell type can substantially change the specific response. Co-activation or alternate activation of $\mathrm{G}_{\mathrm{o}}$ or $\mathrm{G}_{\mathrm{q}}$ has been repeatedly observed [77-79]. In some cases, including studies in transfected cells, other $\mathrm{G}$ proteins such as $G_{z}$ or $G_{16}$ were reported to couple differentially to melatonin receptors [79-81]. While coupling to $G_{i}$ protein subforms causes decreases in cAMP, rises in cAMP were also described, e.g., for $\mathrm{Mel}_{1 \mathrm{c}}$ signaling via $\alpha_{\mathrm{z}}$ coupling to adenylyl cyclase type II [82]. $\mathrm{G}_{\mathrm{i}}$-dependent mechanisms may affect not only cAMP levels, but may also modulate, in some cells, $\mathrm{K}^{+}$ conductance, and additionally stimulate, via $\beta \gamma$, phospholipase $\mathrm{C} \beta$ (PLC $\beta$ ), which may also be the case with
$\mathrm{G}_{\mathrm{o}}$ [79]. PLC $\beta$ activation has been observed in SCN slices, too [83], but this seems to be a more general phenomenon of either parallel or alternate melatonin signaling, observed in various target tissues, involving either pertussis toxin-sensitive $\left(\mathrm{G}_{\mathrm{i}} / \mathrm{G}_{\mathrm{o}}\right)$ or insensitive (e.g., $\mathrm{G}_{\mathrm{q}}$ ) $\mathrm{G}$ proteins $[79,84,85]$. Actions via PLC $\beta$ can have numerous consequences, from activation of PKC subforms, CaM kinases, the opening of $\mathrm{Ca}^{2+}$-activated $\mathrm{K}^{+}$channels and modulation of various other protein kinases of the MAP and JNK pathways. However, it should be emphasized (i) that the signaling mechanisms are strongly cell type-dependent because of differences in $\mathrm{G}$ protein subforms and in coupling of $\mathrm{MT}_{1}$ or $\mathrm{MT}_{2}$, (ii) that findings obtained in the $\mathrm{SCN}$ are not always applicable to peripheral organs and vice versa, and (iii) that the signaling via $\mathrm{MT}_{1}$ or $\mathrm{MT}_{2}$ can even have opposite effects. An impressive example is vasomotor control by melatonin. While actions via $\mathrm{MT}_{1}$ cause a pertussis toxin-sensitive vasoconstriction by opening of $\mathrm{BK}_{\mathrm{Ca}}$ channels, those via $\mathrm{MT}_{2}$ result in vasodilation [20,68].

Several melatoninergic agonists and antagonists have been developed and used as investigative drugs or, in the case of ramelteon, as an FDA-approved sleeping pill. For reasons of space, this important aspect cannot be discussed here in detail.

\section{Other binding sites}

In addition to the $\mathrm{G}$ protein-coupled receptors, other binding sites of melatonin exist. Their binding affinities are mostly lower than those of $\mathrm{MT}_{1}$ and $\mathrm{MT}_{2}$, but could suffice for physiological responses at elevated concentrations that seem to be present in several tissues. In at least one case, this extends beyond the animals, so that high concentrations of melatonin found in unicells, fungi and some plants may act via non-membrane binding sites.

One of the melatonin-binding proteins was originally believed to be another membrane receptor and named $\mathrm{MT}_{3}$, but it turned out to be a mainly cytosolic enzyme, quinone reductase $2(=\mathrm{QR} 2=\mathrm{NRH}$ :quinone oxidoreductase $2=\mathrm{NQO} 2 ; \mathrm{NRH}=$ dihydronicotinamide riboside) [86-88]. The enzyme is expressed in several tissues, including the brain [87]. Some of its polymorphic subforms have been related to Parkinson's disease [89]. Disruption of the NQO2 gene leads to bone marrow myeloid hyperplasia [90]. This indicates a role beyond detoxification of xenobiotics. The frequently proposed assumption of a role in redox metabolism, eventually in terms of protection, is actually nothing more than an idea. Even though a function in ubiquinone reduction has been suggested, the precise role of this enzyme is not really understood 
[91]. Recently, melatonin was assumed to be a cosubstrate serving as a hydrogen/electron donor to other redox co-factors such as FAD [92], a concept still requiring further experimental support. It should also be noted that NAS has an affinity for NQO2 comparable to that of melatonin [cf. discussion in ref. 20].

A melatonin-binding protein of considerable regulatory significance is calmodulin. Its affinity to melatonin is sufficient for mediating effects at elevated physiological concentrations, especially those attained in tissues [93-95]. Melatonin binding results in inhibitions of CaM kinase II [94] and of neuronal NO synthase [96]. Moreover, melatonin causes PKC $\alpha$-dependent phosphorylation of calmodulin [97], presumably by signaling mechanisms described in the preceding section, but this effect is important insofar as it perpetuates CaM-dependent inhibitions. Interacting calmodulin and kinase effects are relevant to rearrangements of the cytoskeleton [95], which represent some of the earliest effects described for melatonin, including ciliates and plants $[8,96]$. An additional facette of melatonin/ $/ \mathrm{Ca}^{2+}$ interactions is the binding to calreticulin, and, perhaps, to two nuclear proteins, one of which had high homology to calreticulin, whereas the other was structurally different [98].

Nuclear binding sites of melatonin have been a matter of considerable debate. Meanwhile, many publications have dealt with transcription factors belonging to the retinoic acid receptor superfamily, in particular, ROR $\alpha 1$, ROR $\alpha 2$ and RZR $\beta$ [99-102], and their classification as nuclear receptors seems justified, although their affinity to melatonin is lower. A synthetic ligand, CGP 52608 [99], has been repeatedly used for identifying effects by these nuclear proteins. ROR $\alpha 1$ and $R O R \alpha 2$ seem to be involved in some aspects of immune modulation, and RZR $\beta$ is expressed in the central nervous system, including the pineal gland $[20,102]$. Moreover, ROR $\alpha$ was assumed to mediate upregulations of antioxidant enzymes [101]. Still, the full spectrum and physiological meaning of these receptors remains to be clarified.

A further melatonin binding site seems to exist in rat brain mitochondria, for which a dissociation constant of $150 \mathrm{pM}$ and a total number of specific binding sites of $30 \mathrm{fmol} / \mathrm{mg}$ have been determined [20]. The protein is assumed to be localized at the amphipathic ramp of complex I in the mitochondrial electron transport chain. At elevated concentrations, melatonin was also shown to directly inhibit the opening of the mitochondrial permeability transition pore [103], a finding that would imply an additional, low-affinity mitochondrial binding site.
Although a considerable amount of clarification is required concerning the binding sites different from the $\mathrm{G}$ protein-coupled receptors, the findings mentioned in this section collectively indicate that melatonin is much more pleiotropic than previously believed, not only with regard to the numerous target organs, $G$ proteins and $G$ protein-regulated proteins involved, but also to additional signaling mechanisms.

\section{Tissue versus circulating melatonin}

The consequences of extrapineal melatonin biosynthesis merit particular consideration because they profoundly change our view of the biological role of this molecule. Absence of robust melatonin rhythms or low-amplitude variations imply roles different from the transmission of dark signals. In tissues containing considerably higher levels than in the circulation, a protective role may be assumed. Numerous antioxidant, antiinflammatory, antiexcitatory/antiexcitotoxic and oncostatic effects have been reported in countless publications and have been frequently reviewed [8, 20, 27, 31, 91, 96, 102,104, 105]. Although many of these investigations have been conducted at high doses, they are not collectively physiologically irrelevant, especially when tissue concentrations are approaching the micromolar range, or when protection by melatonin has been demonstrated at levels found in the circulation $[20,96]$.

In organs which contain melatonin above plasma levels, but poorly release the indoleamine, an answer has to be given as to why melatonin is not - or only in low quantities - entering the circulation, although it is usually believed to cross any membrane because of its amphiphilicity [27, 91, 105]. If tissue concentrations have been determined correctly, the answer can only be that of sequestration by non-receptor binding sites [20]. It cannot be said with certainty whether the major proteins involved have already been identified, but the binding to calreticulin [98] and to abundant nuclear proteins [106] may contribute to melatonin retention.

Low-amplitude rhythms or absence of (robust) rhythms in some tissues can resolve another paradox, namely, why nocturnally peaking melatonin should exert protective effects in both day- and night-active animals, whereas reactive oxygen and nitrogen species are preferentially produced in circadian phases of motor and neuronal activity. If rhythmicity is poorly expressed in an organ or almost absent, the circadian phase loses its relevance for tissue melatonin, and only the generation of reactive intermediates becomes decisive for a phase of detoxification [91, 105]. 
High amounts of tissue melatonin - cf. the several hundred-fold quantities in the gastrointestinal tract compared to the pineal - has another important consequence, which is at variance with the frequently read statement that melatonin is almost quantitatively metabolized in the liver to 6-hydroxymelatonin, with subsequent conjugation and excretion as 6-sulfatoxymelatonin. This may be true for the circulating hormone and for single intravenous injections, but has already turned out to be wrong in the infusion experiment [28]. Release of non-metabolized melatonin to the intestinal lumen has been shown repeatedly $[26,28-30]$. With regard to the manyfold higher quantities outside pineal and circulation, hepatic 6hydroxylation as an almost exclusive pathway appears extremely illogical. That statement also negates longknown alternate pathways of melatonin metabolism (Fig. 2), such as demethylation by the $\mathrm{P}_{450}$ isoforms CYP2C19 and, to a much smaller extent, CYP1A2; deacetylation by aryl acylamidases, melatonin deacetylases or eserine-sensitive acetylcholinesterase, and pyrrole-ring cleavage $[20,102]$. Their relevance in the central nervous system was recently reviewed [20]. In the spinal cord, an inhibitory effect of melatonin on nociceptive transmission was maintained by eserine [107]. In Xenopus melanophores, a loss of responsiveness to melatonin was prevented by the same drug [108]. Other recent estimations of quantitative melatonin metabolism came to the conclusion that about one-third of the indoleamine is converted by pyrrolering cleavage to methoxylated kynuramines (Fig. 2) [109]. The rates may be even higher in some tissues in which $\mathrm{P}_{450}$ enzymes are poorly expressed [27]. These kynuramines had already been shown decades ago to represent major melatonin metabolites in the brain, whereas no 6-hydroxymelatonin was detected in that study [22], although 6-hydroxylation should be possible in the brain because of the presence of CYP1B1 [110] and may have been overlooked at that time. These findings are of particular importance insofar as melatonin is released from the pineal gland not only to the circulation, but also, at much higher concentrations, via the pineal recess into the third ventricle [111, 112]. Since melatonin concentrations in the cerebrospinal fluid obtained from lumbal puncture are in the range of serum levels, most of the compound must have been either taken up or metabolized by the brain tissue before entering the spinal cord.

\section{Complexity of metabolism}

$\mathrm{P}_{450}$ enzymes are organ specifically expressed and catalyze hydroxylation or dealkylation. The 6-hydroxylating subforms, CYP1A2, and with smaller contri- butions, CYP1A1 and CYP1B1 [110], are present in the liver, but are found in other tissues too. The major demethylating subform, CYP2C19, is also expressed in the liver [110]. After oral melatonin administration to mice, NAS amounted to only about $3 \%$ of the urinary metabolites [113].

Deacetylation to 5-MT leads to another bioactive molecule. Contrary to melatonin and NAS, this molecule is a substrate of monoamine oxidase A (MAO A), and the resulting oxidation product, 5methoxyindole-3-acetaldehyde, is converted by aldehyde dehydrogenase to 5-MIAA, or by alcohol dehydrogenase to 5-ML (Fig. 2), two compounds which are also formed by $O$-methylation of 5hydroxylated analogs [20]. These metabolites are not restricted to vertebrates, but are also produced in dinoflagellates and, 5-ML at least, in brown algae, red algae and yeast $[8,10,42]$. While 5-MIAA seems to be an end product, which is excreted, 5-ML has been considered as another bioactive molecule. A further 5-MT metabolite, the $\beta$-carboline pinoline, known as a psychotropic drug interfering with serotonin availability, will not be discussed here because a considerable fraction is artificially formed during extraction.

$\mathrm{N}, \mathrm{N}$-dimethyl-5-methoxytryptamine, which is either produced from 5-MT or by $O$-methylation of bufotenin, has properties of an endogenous hallucinogen [20]. $O$-acetyl-5-methoxytryptophol, a structural melatonin homolog, is formed from 5-ML in organs containing high melatonin concentrations, such as the pineal gland. Several pharmacological effects comprise inhibition of nicotinic and muscarinic acetylcholine receptors as well as decreases in pituitary prolactin and luteinizing hormone [20].

The metabolic route of pyrrole-ring cleavage (Fig. 2) leads to the 5-methoxylated kynuramines, $N^{1}$-acetyl$N^{2}$-formyl-5-methoxykynuramine (AFMK) and $N^{1}$ acetyl-5-methoxykynuramine (AMK). AFMK can be formed either directly from melatonin or indirectly from a tricyclic metabolite, cyclic 3-hydroxymelatonin (c3OHM). c3OHM is a product of melatonin oxidation by free radicals, in particular, by sequential interactions with two hydroxyl radicals $[114,115]$. It is found in rodent urine after melatonin administration [113], and is strongly elevated after exposure to ionizing radiation [114]. It is a remarkable fact that numerous reactions of melatonin lead to the same product, AFMK, and that this kynuramine is frequently the major product in various oxidation systems, especially when they are designed in a way not to generate a single radical species, but to consider the physiological prevalence of superoxide anions $[115,116]$, which can serve as terminators of radical reaction chains $[8,115,116]$. The spectrum of reac- 


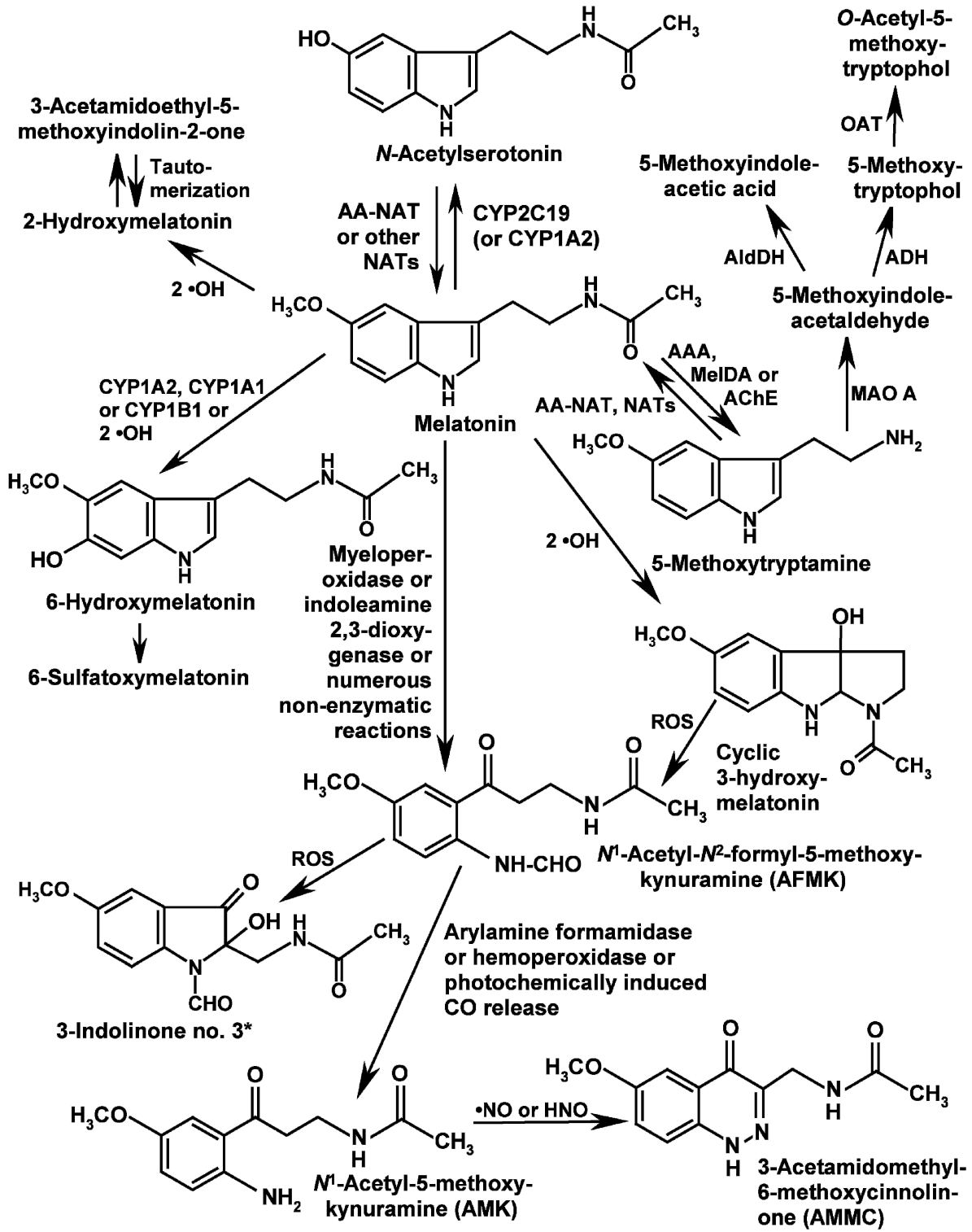

Figure 2. The complexity of melatonin metabolism. AAA, aryl acylamidase; AA-NAT, arylalkylamine $\quad N$-acetyltransferase; AChE, acetylcholinesterase; $\mathrm{ADH}$, alcohol dehydrogenase; AldDH, aldehyde dehydrogenase; CYP, cytochrome $\mathrm{P}_{450}$ isoform (monoxygenase or dealkylase); HNO, nitroxyl; MelDA, melatonin deacetylase; NATs, $\mathrm{N}$-acetyltransferases (other than AA-NAT); NO, nitric oxide radical; OAT, $O$-acetyltransferase; -OH, hydroxyl radical; ROS, reactive oxygen species. *Full name: $N$-(1-formyl-2-hydroxy-5methoxy-3-oxo-2,3-dihydro-1Hindol-2-ylmethyl)-acetamide; additional non-hydroxylated and deformylated 3-indolinones have been identified as AFMK metabolites and chemically characterized [123]. Additional reactions and metabolites, which also exist, have not been included. tions leading to AFMK is exceptional. It comprises enzymes, such as indoleamine 2,3-dioxygenase or, quantitatively important, myeloperoxidase [109], pseudoenzymatic catalysis by hypervalent oxyferrylhemoglobin or hemin, and various photochemical and radical reactions $[10,105,117]$.

The quantitative relevance of AFMK and AMK seems to have been underrated for quite some time. Apart from the widely neglected demonstration of these kynuramines as major melatonin metabolites in the brain [22], it may be a misconception to judge their significance on the basis of urinary or plasma concentrations. Only small amounts of AFMK and AMK were found in the urine upon oral administration of melatonin [113], but, in stark contrast, high quantities were found after injection into the cisterna magna [22]. The low urinary quantities detected in some experiments or in untreated animals should be seen in relation to administration routes, formation in tissues and the metabolic fate of the kynuramines, which may not become apparent in body fluids. High concentrations of AFMK have been found in HaCaT keratinocytes [36]. One might also note high amounts and circadian rhythmicity of AFMK found in a plant, the water hyacinth, Eichhornia crassipes [118]. At lower physiological concentrations of melatonin, the role of its oxidation by free radicals may largely be seen in the formation of AFMK and its secondary metabolites [91, 105].

Other products deriving from melatonin by radical reactions are hydroxylated indoles, whereas dimers are relatively rare because of the methoxy group, which largely prevents the formation of $O$-centered and $C$-centered indolyl radicals $[22,105]$. Preferential 
sites of hydroxylations have been identified [119] Apart from c3OHM, 6-hydroxy- and 2-hydroxymelatonin can be formed, the latter being in equilibrium with its tautomer, $N$-acetyl-5-methoxy-2-indolinone [120].

Deformylation of AFMK to AMK is catalyzed by two enzymes, arylamine formamidase [27, 102, 105] and hemoperoxidase ('catalase') [105, 121]. Recently, another photochemical mechanism by UV light (Fig. 2) has been described [122]. AMK formation may not be an exclusive route of AFMK metabolism, since free-radical reactions also led to a couple of $\mathrm{C} 2$ substituted 3-indolinones (Fig. 2), representing a novel class of oxidation products [123].

While AMK was regarded for decades as an end product because of its appearance in the urine, this seems rather unlikely, since AMK was shown to be easily oxidized [124] and to readily interact with reactive nitrogen species. Even the dry solid forms new products with trace gases present in the air, when exposed on the large surface of a silica gel. Two products are formed in solution by reactive intermediates present in biological material, a nitrosated derivative, 3-acetamidomethyl-6-methoxycinnolinone (AMMC) (Fig. 2), and a nitrated compound, $N^{1}$ acetyl-5-methoxy-3-nitrokynuramine $\quad(\mathrm{AMNK}=3$ nitro-AMK) [125]. AMMC is generated by all three different $\mathrm{NO}$ congeners, $\cdot \mathrm{NO}, \mathrm{NO}^{+}$and $\mathrm{HNO}$, although the reaction with $\mathrm{NO}^{+}$is physiologically less likely, because of the short half-life of the cation in aqueous solution at $\mathrm{pH}$ 7.4 [126]. AMMC represents a stable compound, contrary to the majority of other $\mathrm{N}$ nitrosated substances [127], including $N$-nitrosomelatonin, which easily redonate NO. AMNK was found to be produced by the combination of peroxynitrite and $\mathrm{CO}_{2}$, a physiological nitrating mixture leading to carbonate radicals $\left(\mathrm{CO}_{3} \cdot{ }^{-}\right)$and $\cdot \mathrm{NO}_{2}[125]$.

\section{The non-classic actions of melatonin}

Countless publications have dealt with protective actions of melatonin. Although the number of such reports is meanwhile higher than that on its chronobiological role, the understanding in mechanistic terms still awaits further deepening under many aspects. Nevertheless, the high potential of such a function seems worthy of considerable efforts.

Melatonin participates in various lines of defense. A first one is that of antioxidative protection, a phenomenon which has been frequently reviewed [e.g., 8, 27, 91, 96, 101, 102, 104, 105, 119, 121] and will be discussed here only in its general traits. Investigation of the antioxidant actions of melatonin was strongly stimulated by the finding of potent direct scavenging of hydroxyl radicals by this indoleamine [128]. However, antioxidative protection has turned out to be more than radical scavenging. Under physiological conditions, the capability of donating electrons to free radicals - which is present in this molecule without any doubt - may have other biological meanings than to detoxify a certain number of free radicals, already from the viewpoint of stoichiometry. At pharmacological concentrations, the value of melatonin as a direct scavenger has been repeatedly demonstrated (cf. reviews mentioned). Certain cells or organisms containing melatonin concentrations in the (sometimes upper) micromolar range may also profit by direct scavenging. Additional roles may be sought in the non-enzymatic formation of other bioactive compounds and in the capability of undergoing reactions with electron exchanging or transporting systems, such as the respiratory chain [91, 105]. Upregulation of antioxidant and downregulation of - a few prooxidant enzymes [91, 104, 105] certainly contributes to the antioxidant balance, but these effects should not be generally overrated. Induction of hemoperoxidase (catalase), superoxide dismutase subforms, glucose-6-phosphate dehydrogenase and $\gamma$-glutamylcysteine synthase are organ-specific, and the meaning of upregulations of just a few percent, sometimes only demonstrated at the mRNA level, is questionable. A most frequently reported and reliable effect is the stimulation of glutathione peroxidase, as particularly found in the central nervous system. The cellular mechanism of upregulation has only been tentatively addressed [101], but is not really elucidated in its details.

Since detoxification of free radicals and other oxidants did not fully explain the antioxidative efficacy of melatonin, radical avoidance was brought into focus [27, 91, 105]. Formation of reactive oxygen and nitrogen species can be reduced by several actions of melatonin. First, appropriate timing and coordination of rhythms, as favored by the indoleamine, should diminish oxidative stress, because oxidative damage was elevated in the clock mutants, $p^{0} r^{0}$ and $p^{\mathrm{s}} \mathrm{r}^{\mathrm{S}}$ in Drosophila, tau in Syrian hamster [91]. Second, the antiexcitatory/antiexcitotoxic effects of melatonin should reduce radical formation as well, by attenuating their metabolism-related generation and the prevention of $\mathrm{Ca}^{2+}$ - and NO-dependent cellular stress $[91,105]$. In this context, mitochondria seem to be a particular target. These organelles represent in many cells a major source of superoxide anions, due to electron leakage, especially from complexes I and III of the electron transport chain, radicals which are not quantitatively eliminated by mitochondrial and cytosolic superoxide dismutases (MnSOD and $\mathrm{Cu}, \mathrm{Zn}$ SOD). Superoxide anions are sources of peroxynitrite 
from cytosolic or mitochondrially generated $\mathrm{NO}$ and lead, via combination with $\mathrm{CO}_{2}$ or protons, to carbonate $\left(\mathrm{CO}_{3} \cdot{ }^{-}\right)$, hydroxyl $(\cdot \mathrm{OH})$ and $\cdot \mathrm{NO}_{2}$ radicals. $\mathrm{H}_{2} \mathrm{O}_{2}$ formed by the SODs is a source of hydroxyl radicals. Electron overflow at the iron-sulfur cluster N2 of complex I, i.e., at the bottleneck of the transport chain, seems to be an important cause of enhanced superoxide generation. This site is assumed to be modulated by melatonin [27, 91, 105] and may be associated with a mitochondrial high-affinity binding site [20] (cf. section on Other binding sites). Although many details of this concept of mitochondrial radical avoidance remain to be elucidated, pertinent effects of melatonin at the level of this organelle have been repeatedly described, such as support of mitochondrial electron flux, stimulation of complex I and IV activities, prevention of mitochondrial calcium overload and maintenance of mitochondrial membrane potential and of ATP formation [91, 105, 129, 130]. These findings gain particular significance because of normalizations in mitochondrial functions achieved by melatonin in senescence-accelerated mice [131, 132].

Mitochondrial hypoactivity and dysfunction are phenomena associated with aging, but also with numerous diseases. These organelles also play a pivotal role in the induction of apoptosis. Melatonin has been frequently shown to antagonize or prevent apoptosis by modulating mitochondrial functions [133, 134], including effects on calcium homeostasis and mitochondrial membrane potential $[105,134,135]$, and also by directly inhibiting the mitochondrial permeability transition pore [103].

Antiexcitatory and antiexcitotoxic effects are partially related to mitochondria, in terms of avoidance of calcium overload and elevated radical formation in these organelles. These actions, which extend to anticonvulsant and anxiolytic properties [102], go beyond the chronobiotic and sleep-inducing actions and, again, are highly complex. In mammals, modulations of GABA and glutamate signaling are involved and include secondary effects through decreases in cytosolic $\mathrm{Ca}^{2+}$ via $\mathrm{GABA}_{c}$ [136] or metabotropic $\mathrm{mGlu}_{3}$ receptors [137], interference with neuronal NO synthase, directly, or indirectly by AMK [102, 104 105], effects on $\mathrm{K}^{+}$currents, as studied in the cerebellum [138], and potentiation of strychninesensitive glycine-induced currents [139].

Immunomodulation by melatonin represents another line of defense. This includes antiiflammatory properties of the indoleamine, in which antioxidant, NOattenuating, and mitochondrial effects act in concert with the attenuation of proinflammatory signaling. Moreover, melatonin is produced by various leukocytes, such as monocytes, eosinophils, mast cells, natural killer (NK) cells and several leukocyte-derived cell lines [37, 40, 140]. It was also found in thymocytes and epithelial cells [40], but the origin is not clear in these cases. Immunomodulation by melatonin has recently been reviewed several times [e.g., 40, 102, 131, 132]. Main findings are the activation of various cell types, such as T, B and NK cells, monocytes and splenocytes, and modulation of cytokine release. Melatonin was shown to enhance the production of interleukin (IL)-2, IL-6 and IL-12, whereas levels of interferon-8 or tumor necrosisfactor- $\alpha$ were sometimes decreased but in other cases increased [40, 143]. Melatonin also counteracted inhibitory effects of $\mathrm{PGE}_{2}$ on IL-2 production [68, 144]. With regard to the complexity of the immune system, some divergence in effects depending on cell types, differentiation state and mixtures of cells in test systems should not be surprising. In the immune system, different melatonin receptors are involved. $\mathrm{MT}_{1}$ was found to mediate effects concerning IL-2, but the presence of this receptor was demonstrated in numerous leukocyte subtypes [40, 68]. Signaling via $\mathrm{MT}_{2}$ was, e.g. shown to stimulate splenocyte proliferation and to decrease leukocyte rolling [68, 145]. In avian splenocytes, growth stimulation is mediated by the $\mathrm{Mel}_{1 \mathrm{c}}$ receptor [146]. Based on pharmacological criteria, inhibition of leukotriene $\mathrm{B}_{4}$-induced endothelial leukocyte adhesion was ascribed to the binding site previously named $\mathrm{MT}_{3}$ [145], now known to be quinone reductase 2 , but, in the absence of demonstrated signaling pathways, this should be judged with caution. Expression of ROR and RZR subforms has been reported for various leukocytes and related cells such as splenocytes, thymocytes and Jurkat cells, and some of the actions of melatonin seem to be mediated by these transcription factors [100, 141, 142, 147]. High densities of nuclear binding sites, as sometimes observed, should not be immediately taken as a sign for involvement of ROR/RZR receptors, because of other nuclear binding proteins $[98,106]$. In melatoninsynthesizing leukocytes, concentrations may be sufficient for nuclear receptors and mediate autocrine effects. The interplay of membrane and nuclear receptors in the immune system remains an intriguing field.

\section{Actions of metabolites}

Melatonin may also be regarded as a prodrug leading to other bioactive molecules [27]. Earlier studies were mostly oriented at actions already known from melatonin, with the frequent outcome that the metabolites were only effective at higher concentrations [20]. Substances like 5-MT and NAS, being both 
metabolites and precursors, possess high affinities for some 5-HT receptor subforms found in both the central nervous system and the periphery [reviewed in ref. 20]. It is, however, difficult to judge a putative role of these compounds as secondary mediators of melatonin in the CNS, in part because of concentrations, especially in the case of the easily metabolized 5MT, and because NAS is apparently formed without being converted to melatonin and exerts independent actions. The actions of 5-MT in brain and retina have been recently reviewed [20]. More detailed information on profound and ecophysiologically relevant actions by $5-\mathrm{MT}$ in dinoflagellates can be found elsewhere [10, 42].

Actions of non-indolic metabolites have only been decribed for mammals, except for some unpublished, preliminary data on life extension by AFMK in a rotifer, Philodina acuticornis [B. Poeggeler, personal communication]. In the first decades after discovery of AFMK and AMK, some effects were described concerning prolactin release, retardation of testicular growth, binding to benzodiazepine and melatonin receptors [summarized in ref. 148]. Binding affinities were not sufficient to explain actions of the indoleamine by conversion to AFMK or AMK. However, an interesting chronobiological effect of AFMK was described, which was, unfortunately, never followed up in other comparable systems. In rats, AFMK was shown to promote the re-entrainment of the melatonin rhythm [149]. In the taxonomically very distant Lingulodinium, no phase shifting by AFMK was observed [R. Hardeland, unpublished data]. However, the life cycles of malaria parasites (Plasmodium chabaudi and Plasmodium falciparum) were synchronized by AFMK in the upper nanomolar range, an effect which was associated with rises in cytosolic calcium and which was blocked by luzindole [150], otherwise being an $\mathrm{MT}_{1} / \mathrm{MT}_{2}$ melatonin receptor antagonist. The inhibition by luzindole may raise questions concerning conclusions on melatonin signaling via $\mathrm{MT}_{1}$ and/or $\mathrm{MT}_{2}$ in other cases, or on a cryptic, perhaps indirect action of AFMK at these receptors.

AMK was shown to efficiently inhibit prostaglandin synthesis [151], a property of, perhaps, considerable pharmacological interest. At the time of discovery, cyclooxygenases (COX) 1 and 2 were not distinguished, but the efficacy of AMK was reported to be far higher than that of acetylsalicylic acid (aspirin). Recently, AMK was reported to downregulate COX-2 - but not COX-1 - expression in macrophages, an effect shared by its precursors AFMK and melatonin [152]. Whether antiinflammatory or other immunological actions by 5-methoxylated kynuramines may be of medicinal relevance, remains to be studied. In cases of viral meningitis, considerably enhanced levels of AFMK in the cerebrospinal fluid correlated with inflammatory markers such as tumor necrosis factor- $\alpha$, IL- 8 and IL- $1 \beta$ [153]. This may only reflect rises in cerebral melatonin oxidation. However, AFMK was also reported to be a more efficient inhibitor of lipopolysaccharide (LPS)-induced production of TNF- $\alpha$ and IL-8 in neutrophils, compared to melatonin [154], an effect which cannot be explained by affinity or selectivity to free radicals released in response to LPS.

AFMK was also used to antagonize oxidative stress, at pharmacological concentrations. It was shown to protect DNA from oxidative damage by hydroxyl radicals generated by a chromium(III)-based Fentonanalog reaction [155], or by a $\delta$-aminolevulinic acid/ $\mathrm{Fe}^{2+}$ system [156], but it remained less efficient than melatonin. This is not surprising because AFMK exhibits a preference for two-electron transfer reactions [117] and is, therefore, a poorer radical scavenger than melatonin or its deformylated metabolite, AMK, which easily undergoes single-electron transfer reactions [105, 124]. Thus, protective effects by AFMK observed in living cells, such as inhibition of toxicity by glutamate, $\mathrm{H}_{2} \mathrm{O}_{2}$, or amyloid $\beta_{25-35}$ peptide in hippocampal neurons [117], might be the consequence of its conversion to AMK. The same may hold for protection against oxidative damage to DNA, proteins and lipids by X-rays [157]. Protective actions by AMK are more than just radical scavenging, because of additional effects already found at very low, nanomolar or even lower concentrations. Support of mitochondrial functions was observed in the nanomolar range [130]. AMK, being an amphiphilic compound with a slightly higher lipophilicity than melatonin, has been suggested to participate in an electron shuttle, which may bridge bottlenecks in the electron transport chain and, thereby, diminish electron leakage [91, 105]. Attention may also be directed to the structural similarities between ubiquinones and AMK [91]. Moreover, AMK was shown to be a highly efficient inhibitor of neuronal NO synthase, with an $\mathrm{IC}_{50}$ in the nanomolar range, but demonstrable efficacy already at $10^{-11} \mathrm{M}$ [158].

With regard to specific actions of kynuramines, it should be remembered that this chemical family represents its own, though frequently forgotten, class of biogenic amines, including 5-hydroxylated, C5unsubstituted, and $N, N$-dimethylated compounds, for which various effects have been described [148]. Other products from the kynuric pathway of melatonin metabolism may additionally contribute to a complex action spectum. The group of cinnolines, to which AMMC belongs, contains pharmacologically active compounds, which have been used as medica- 
ments or investigative drugs, because of their antiallergic, antitumor, anxiolytic and other neurotropic properties [125].

\section{Conclusions}

The diversity of melatonin actions, the number of demonstrated or putative binding sites, differential $\mathrm{G}$ protein coupling, the existence of numerous target cells and organs, pineal and extrapineal formation and the possibility of additional actions by its metabolites demonstrate an exceptional pleiotropy. This may reflect an orchestrating function, but may also become a problem when specific actions are desired, in terms of both experimental and applied approaches. In practice, multiple effects can hardly be avoided. Whether they are really disadvantagous for a treated organism, or dangerous, remains to be studied.

As a substance found in numerous phylogenetically very distant organisms, at levels differing considerably from taxa to taxa, a uniform spectrum of actions should not be expected, although some themes, such as calmodulin signaling or antioxidant actions, may go across the multitude of species synthesizing this indoleamine. Various findings indicate that it is not generally a compound found only in traces - as in the circulation. Micromolar levels can be present outside the vertebrates, and some findings indicate that tissue melatonin may be sometimes much higher than the blood level. Additional complexity results from different sites of formation in a vertebrate body, which, again, exceeds the classic sites of biosynthesis. The consequences of tissue melatonin and its different fate from that of the circulating hormone deserves further attention. Actions of melatonin metabolites other than 6-hydroxy-/6-sulfatoxymelatonin are a promising field awaiting further research, especially with regard to the central nervous system. This holds, in particular, for major brain metabolites like AMK and its derivatives, perhaps also for 5-MT. Investigators should not simply direct their attention to effects already known for melatonin, but rather seek for independent actions. As melatonin is not only a hormone, its levels and those of its metabolites should not only and primarily be determined in body fluids but rather in tissues, and differences in administration routes deserve particular consideration.

1 Lerner, A. B., Case, J. D., Takahashi, Y., Lee, T. H. and Mori, W. (1958) Isolation of melatonin, the pineal gland factor that lightens melanocytes. J. Am. Chem. Soc. 80, 2587-2592.

2 Ruffin, N. E., Reed, B. L. and Finnin, B. C. (1969) The specificity of melatonin as a melanophore controlling factor in the pencil fish. Life Sci. 8, 1167-1174.
3 Quay, W. B. (1964) Circadian and estrous rhythms in pineal melatonin and 5-hydroxy indole-3-acetic acid. Proc. Soc. Exp. Biol. Med. 115, 710-713.

4 Axelrod, J., Wurtman, R. J. and Winget, C. M. (1964) Melatonin synthesis in the hen pineal and its control by light. Nature 201, 1134.

5 Lewy, A. J., Wehr, T. A., Goodwin, F. K., Newsome, D. A. and Markey, S. P. (1980) Light suppresses melatonin secretion in humans. Science 210, 1267-1269.

6 Binkley, S. (1993) Structures and molecules involved in generation and regulation of biological rhythms in vertebrates and invertebrates. Experientia 49, 648-653.

7 Klein, D. C. (2007) Arylalkylamine $N$-acetyltransferase: 'the timezyme'. J. Biol. Chem. 282, 4233-4237.

8 Hardeland, R. and Fuhrberg, B. (1996) Ubiquitous melatonin - presence and effects in unicells, plants and animals. Trends Comp. Biochem. Physiol. 2, 25-45.

9 Hardeland, R. and Poeggeler, B. (2003) Non-vertebrate melatonin. J. Pineal Res. 34, 233-241.

10 Hardeland, R., Pandi-Perumal S. R. and Poeggeler, B. (2007) Melatonin in plants - focus on a vertebrate night hormone with cytoprotective properties. Funct. Plant Sci. Biotechnol. 1, 32-45.

11 Dubocovich, M. L. (1983) Melatonin is a potent modulator of dopamine release in the retina. Nature 306, 782-784.

12 Cahill, G. M. and Besharse, J. C. (1989) Retinal melatonin is metabolized within the eye of Xenopus laevis. Proc. Natl. Acad. Sci. USA 86, 1098-1102.

13 Kazula, A., Nowak, J. Z. and Iuvone, P. M. (1993) Regulation of melatonin and dopamine biosynthesis in chick retina: the role of GABA. Vis. Neurosci. 10, 621-629.

14 Buzzell, G. R., Pangerl, A., Pangerl, B., Menéndez-Peláez, A., Vaughan, M. K., Little, J. C., Hill, S. M., Vaughan, G. M. and Reiter, R. J. (1990) Melatonin and porphyrin in the harderian glands of the Syrian hamster: circadian patterns and response to autumnal conditions. Int. J. Biochem. 22, 14651469.

15 Payne, A. P. (1994) The harderian gland: a tercentennial review. J. Anat. 185, 1-49.

16 Djeridane, Y. and Touitou, Y. (2001) Melatonin synthesis in the rat Harderian gland: age- and time-related effects. Exp. Eye Res. 72, 487-492.

17 Tosini, G. and Menaker, M. (1998) Multioscillatory circadian organization in a vertebrate, Iguana iguana. J. Neurosci. 18, $1105-1114$

18 Zawilska, J. B., Berezinska, M., Rosiak, J., Skene, D. J., Vivien-Roels, B. and Nowak, J. Z. (2004) Suppression of melatonin biosynthesis in the chicken pineal gland by retinally perceived light - involvement of D1-dopamine receptors. J. Pineal Res. 36, 80-86.

19 Grace, M. S. and Besharse, J. C. (1993) Solubilization and biochemical characterization of the melatonin deacetylase from Xenopus laevis retina. J. Neurochem. 60, 990-999.

20 Hardeland, R. and Poeggeler, B. (2007) Actions of melatonin, its structural and functional analogs in the central nervous system and the significance of metabolism. Cent. Nerv. Syst. Agents Med. Chem. 7, 289-303.

21 Iuvone, P. M., Gan, J. and Alonso-Gómez, A. L. (1995) 5Methoxytryptamine inhibits cyclic AMP accumulation in cultured retinal neurons through activation of a pertussis toxin-sensitive site distinct from the $2-\left[{ }^{125} \mathrm{I}\right]$ iodomelatonin binding site. J. Neurochem. 64, 1892-1895.

22 Hirata, F., Hayaishi, O., Tokuyama, O. and Senoh, S (1974) In vitro and in vivo formation of two new metabolites of melatonin. J. Biol. Chem. 249, 1311-1313.

23 Menendez-Pelaez, A, Rodriguez, C. and Dominguez, P. (1991) 5-aminolevulinate synthase mRNA levels in the Harderian gland of Syrian hamsters: correlation with porphyrin concentrations and regulation by androgens and melatonin. Mol. Cell. Endocrinol. 80, 177-182.

24 Matsubara, E., Bryant-Thomas, T., Pacheco Quinto, J., Henry, T. L., Poeggeler, B., Herbert, D., Cruz-Sanchez, F., 
Chyan, Y.-J., Smith, M. A., Perry, G., Shoji, M., Abe, K., Leone, A., Grundke-Ikbal, I., Wilson, G. L., Ghiso, J., Williams, C., Refolo, L. M., Pappolla, M. A., Chain, D. G and Neria, E. (2003) Melatonin increases survival and inhibits oxidative and amyloid pathology in a transgenic model of Alzheimer's disease. J. Neurochem. 85, 1101-1108.

25 Huether, G. (1993) The contribution of extrapineal sites of melatonin synthesis to circulating melatonin levels in higher vertebrates. Experientia 49, 665-670.

26 Bubenik, G. A. (2002) Gastrointestinal melatonin: localization, function, and clinical relevance. Dig. Dis. Sci. 47, 23362348.

27 Hardeland, R. and Pandi-Perumal, S. R. (2005) Melatonin, a potent agent in antioxidative defense: actions as a natural food constituent, gastrointestinal factor, drug and prodrug. Nutr. Metab. (Lond.) Sep. 10, 2-22.

28 Messner, M., Hardeland, R., Rodenbeck, A. and Huether, G. (1998) Tissue retention and subcellular distribution of continuously infused melatonin in rats under near physiological conditions. J. Pineal Res. 25, 251-259.

29 Tan, D.-X., Manchester, L. C., Reiter, R. J., Qi, W., Hanes, M. A. and Farley, N. J. (1999) High physiological levels of melatonin in the bile of mammals. Life Sci. 65, 2523-2529.

30 Bubenik, G. A., Hacker, R. R., Brown, G. M. and Bartos, L. (1999) Melatonin concentrations in the luminal fluid, mucosa and muscularis of the bovine and porcine gastrointestinal tract. J. Pineal Res. 26, 56-63.

31 Tan, D.-X., Manchester, L. C., Hardeland, R., Lopez-Burillo, S., Mayo, J. C., Sainz, R. M. and Reiter, R. J. (2003) Melatonin - a hormone, a tissue factor, an autocoid, a paracoid, and an antioxidant vitamin. J. Pineal Res. 34, 75-78.

32 Huether, G., Poeggeler, B., Reimer, A. and George, A. (1992) Effect of tryptophan administration on circulating melatonin levels in chicks and rats: evidence for stimulation of melatonin synthesis and release in the gastrointestinal tract. Life Sci. 51, 945-953.

33 Slominski, A., Fischer, T. W., Zmijewski, M. A., Wortsman, J. Semak, I., Zbytek, B., Slominski, R. M. and Tobin, D. J. (2005) On the role of melatonin in skin physiology and pathology. Endocrine 27, 137-148.

34 Gaudet. S. J., Slominski, A., Etminan, M., Pruski, D., Paus, R and Namboodiri, M.A. (1993) Identification and characterization of two isozymic forms of arylamine $\mathrm{N}$-acetyltransferase in Syrian hamster skin. J. Invest. Dermatol. 101, 660-665.

35 Slominski, A., Pisarchik, A., Semak, I., Sweatman, T. and Wortsman, J. (2003) Characterization of the serotoninergic system in the C57BL/6 mouse skin. Eur. J. Biochem. 270, 3335-3344.

36 Fischer TW, Sweatman TW, Semak I, Sayre RM, Wortsman J, Slominski A. (2006) Constitutive and UV-induced metabolism of melatonin in keratinocytes and cell-free systems FASEB J. 20, 1564-1566. Erratum in FASEB J. 21, 630.

37 Conti, A., Conconi, S., Hertens, E., Skwarlo-Sonta, K. Markowska, M. and Maestroni, G. J. M. (2000) Evidence for melatonin synthesis in mouse and human bone marrow cells. J. Pineal Res. 28, 193-202.

38 Maestroni, G. J. M., Zammaretti, F. and Pedrinis, E. (1999) Hematopoietic effect of melatonin involvement of type 1 kappa-opioid receptor on bone marrow macrophages and interleukin-1. J. Pineal Res. 27, 145-153.

39 Hardeland, R. (1997) Melatonin: multiple functions in signaling and protection. In: Skin Cancer and UV Radiation, pp. 186-198, Altmeyer, P., Hoffmann, K., and Stücker, M. (eds), Springer, Berlin

40 Carrillo-Vico, A., Guerrero, J. M., Lardone, P. J. and Reiter, R. J. (2005) A review of the multiple actions of melatonin on the immune system. Endocrine 27, 189-200.

41 Kvetnoy, I. M. (1999) Extrapineal melatonin: location and role within diffuse neuroendocrine system. Histochem. J. 31 , $1-12$.

42 Hardeland, R. (1999) Melatonin and 5-methoxytryptamine in non-metazoans. Reprod. Nutr. Dev. 39, 399-408.
43 Callebert, J., Jaunay, J.-M. and Jallon, J.-M. (1991) Control of Drosophila biorhythms. Adv. Pineal Res. 5, 81-84.

44 Liu, T. and Borjigin, J. (2005) N-acetyltransferase is not the rate-limiting enzyme of melatonin synthesis at night. J. Pineal Res. 39, 91-96.

45 Kikuchi, T., Raju, K., Breitman M. L. and Shinohara, T. (1993) The proximal promoter of the mouse arrestin gene directs gene expression in photoreceptor cells and contains an evolutionarily conserved retinal factor-binding site. Mol. Cell. Biol. 13, 4400-4408.

46 Appelbaum, L., Vallone, D., Anzulovich, A., Ziv, L., Tom, M., Foulkes, N. S. and Gothilf, Y. (2006) Zebrafish arylalkylamine- $N$-acetyltransferase genes - targets for regulation of the circadian clock. J. Mol. Endocrinol. 36, 337-347.

47 Gamse, J. T., Shen Y. C., Thisse, C., Thisse, B., Raymond, P. A., Halpern, M. E. and Liang, J. O. (2002) Otx5 regulates genes that show circadian expression in the zebrafish pineal complex. Nat. Genet. 30, 117-121.

48 Muñoz, E., Brewer, M. and Baler, R. (2006) Modulation of BMAL/CLOCK/E-Box complex activity by a CT-rich cisacting element. Mol. Cell. Endocrinol. 252, 74-81.

49 Roseboom, P. H., Coon, S. L., Baler, R., McCune, S. K., Weller, J. L. and Klein, D. C. (1996) Melatonin synthesis: analysis of the more than 150 -fold nocturnal increase in serotonin $N$-acetyltransferase messenger ribonucleic acid in the rat pineal gland. Endocrinology 137, 3033-3045.

50 Koch, M., Mauhin, V., Stehle, J. H., Schomerus, C. and Korf, H. W. (2003) Dephosphorylation of pCREB by protein serine/ threonine phosphatases is involved in inactivation of Aanat gene transcription in rat pineal gland. J. Neurochem. 85, 170179.

51 Karolczak, M., Korf, H. W. and Stehle, J. H. (2005) The rhythm and blues of gene expression in the rodent pineal gland. Endocrine 27, 89-100.

52 Ganguly, S., Gastel, J. A., Weller, J. L., Schwartz, C., Jaffe, H., Namboodiri, M. A., Coon, S. L., Hickman, A. B., Rollag, M., Obsil, T., Beauverger, P., Ferry, G., Boutin, J. A. and Klein, D. C. (2001) Role of a pineal cAMP-operated arylalkylamine $N$ acetyltransferase/14-3-3-binding switch in melatonin synthesis. Proc. Natl. Acad. Sci. USA 98, 8083-8088.

53 Choi, B. H., Chae, H. D., Park, T. J., Oh, J., Lim, J., Kang, S. S., Ha, H. and Kim, K. T. (2004) Protein kinase C regulates the activity and stability of serotonin $\mathrm{N}$-acetyltransferase. J. Neurochem. 90, 442-454.

54 Schomerus, C., Korf, H. W., Laedtke, E., Weller, J. L. and Klein, D. C. (2000) Selective adrenergic/cyclic AMP-dependent switch-off of proteasomal proteolysis alone switches on neural signal transduction: an example from the pineal gland. J. Neurochem. 75, 2123-2132.

55 Stehle, J. H., von Gall, C. and Korf, H. W. (2001) Analysis of cell signalling in the rodent pineal gland deciphers regulators of dynamic transcription in neural/endocrine cells. Eur. J. Neurosci. 14, 1-9.

56 Kim, T. D., Kim J. S., Kim, J. H., Myung, J., Chae, H. D., Woo, K. C., Jang, S. K., Koh, D. S. and Kim, K. T. (2005) Rhythmic serotonin $\mathrm{N}$-acetyltransferase mRNA degradation is essential for the maintenance of its circadian oscillation. Mol. Cell. Biol. 25, 3232-3246.

57 Iuvone, P. M., Tosini, G., Pozdeyev, N., Haque, R., Klein, D. C. and Chaurasia, S. S. (2005) Circadian clocks, clock networks, arylalkylamine $\mathrm{N}$-acetyltransferase, and melatonin in the retina. Prog. Retin. Eye Res. 24, 433-456.

58 Chaurasia SS, Haque R, Pozdeyev N, Jackson CR, Iuvone PM. (2006) Temporal coupling of cyclic AMP and Ca/calmodulinstimulated adenylyl cyclase to the circadian clock in chick retinal photoreceptor cells. J. Neurochem. 99, 1142-1150.

59 Perreau-Lenz, S., Kalsbeek, A., Garidou, M. L., Wortel, J., van der Vliet, J., van Heijningen, C., Simonneaux, V., Pévet, P. and Buijs, R. M. (2003) Suprachiasmatic control of melatonin synthesis in rats: inhibitory and stimulatory mechanisms. Eur. J. Neurosci. 17, 221-228. 
60 Chik, C. L., Liu Q. Y., Li, B., Klein, D. C., Zylka, M., Kim, D S., Chin, H., Karpinski, E. and Ho, A. K. (1997) $\alpha_{1 \mathrm{D}}$ L-type $\mathrm{Ca}^{2+}$-channel currents: inhibition by a $\beta$-adrenergic agonist and pituitary adenylate cyclase-activating polypeptide (PACAP) in rat pinealocytes. J. Neurochem. 68, 1078-1087.

61 von Gall, C., Lewy, A., Schomerus, C., Vivien-Roels, B. Pevét, P., Korf, H. W. and Stehle, J. H. (2000) Transcription factor dynamics and neuroendocrine signalling in the mouse pineal gland: a comparative analysis of melatonin-deficient C57BL mice and melatonin-proficient $\mathrm{C} 3 \mathrm{H}$ mice. Eur. J. Neurosci. 12, 964-972.

62 Link, W. A., Ledo, F., Torres, B., Palczewska, M., Madsen, T. M., Savignac, M., Albar, J. P., Mellström, B. and Naranjo, J. R. (2004) Day-night changes in downstream regulatory element antagonist modulator/potassium channel interacting protein activity contribute to circadian gene expression in pineal gland. J. Neurosci. 24, 5346-5355.

63 Kim, T. D., Woo, K. C., Cho, S., Ha, D. C., Jang, S. K. and Kim, K. T. (2007) Rhythmic control of AANAT translation by hnRNP Q in circadian melatonin production. Genes Dev. 21, $797-810$

64 Ebisawa, T., Karne, S., Lerner, M. R. and Reppert, S. M. (1994) Expression cloning of a high-affinity melatonin receptor from Xenopus dermal melanophores. Proc. Natl. Acad. Sci. USA 91, 6133-6137.

65 Reppert, S. M., Weaver D. R. and Ebisawa, T. (1994) Cloning and characterization of a mammalian melatonin receptor that mediates reproductive and circadian responses. Neuron 13, 1177-1185.

66 Reppert, S. M., Godson, C., Mahle, C. D., Weaver, D. R. Slaugenhaupt, S. A. and Gusella, J. F. (1995) Molecular characterization of a second melatonin receptor expressed in human retina and brain: the $\mathrm{Mel}_{1 \mathrm{~b}}$ melatonin receptor. Proc. Natl. Acad. Sci. USA 92, 8734-8738.

67 Jin, X., von Gall, C., Pieschl, R. L., Gribkoff, V. K., Stehle, J. H., Reppert, S. M. and Weaver, D. R. (2003) Targeted disruption of the mouse $\mathrm{Mel}_{1 \mathrm{~b}}$ melatonin receptor. Mol. Cell. Biol. 23, 1054-1060.

68 Dubocovich, M. L. and Markowska, M. (2005) Functiona $\mathrm{MT}_{1}$ and $\mathrm{MT}_{2}$ melatonin receptors in mammals. Endocrine 27, $101-110$.

69 Reppert, S. M., Weaver, D. R., Cassone, V. M., Godson, C. and Kolakowski, L.F. Jr. (1995) Melatonin receptors are for the birds: molecular analysis of two receptor subtypes differentially expressed in chick brain. Neuron 15, 1003-1015.

70 Jockers, R., Petit, L., Lacroix, I., de Coppet, P., Barrett, P., Morgan, P. J., Guardiola, B., Delagrange, P., Marullo, S. and Strosberg, A. D. (1997) Novel isoforms of $\mathrm{Mel}_{1 \mathrm{c}}$ melatonin receptors modulating intracellular cyclic guanosine 3',5' monophosphate levels. Mol. Endocrinol. 11, 1070-1081.

71 Hunt, A. E., Al-Ghoul, W. M., Gillette, M. U. and Dubocovich, M. L. (2001) Activation of $\mathrm{MT}_{2}$ melatonin receptors in rat suprachiasmatic nucleus phase advances the circadian clock. Am. J. Physiol. 280, C110 - C118.

72 Liu, C., Weaver, D. R., Jin, X., Shearman, L. P., Pieschl, R. L., Gribkoff, V. K. and Reppert, S. M. (1997) Molecular dissection of two distinct actions of melatonin on the suprachiasmatic circadian clock. Neuron 19, 91-102.

73 Weaver, D. R., Liu, C., Reppert, S. M. (1996) Nature's knockout: the $\mathrm{Mel}_{1 \mathrm{~b}}$ receptor is not necessary for reproductive and circadian responses to melatonin in Siberian hamsters. Mol. Endocrinol. 10, 1478-1487.

74 Schuster, C., Gauer, F., Guerrero, H., Lakhdar-Ghazal, N., Pévet P. and Masson-Pévet, M. (2000) Photic regulation of $\mathrm{mt} 1$ melatonin receptors in the Siberian hamster pars tuberalis and suprachiasmatic nuclei: involvement of the circadian clock and intergeniculate leaflet. J. Neuroendocrinol. 12, 207-216.

75 von Gall, C., Weaver, D. R., Moek, J., Jilg, A., Stehle, J. H. and Korf, H. W. (2005) Melatonin plays a crucial role in the regulation of rhythmic clock gene expression in the mouse pars tuberalis. Ann. NY Acad. Sci. 1040, 508-511.
76 Poirel, V. J., Cailotto, C., Streicher, D., Pévet, P., MassonPévet, M. and Gauer, F. (2003) $\mathrm{MT}_{1}$ melatonin receptor mRNA tissular localization by PCR amplification. Neuroendocrinol. Lett. 24, 33-38.

77 Brydon, L., Roka, F., Petit, L., de Coppet, P., Tissot, M., Barrett, P., Morgan, P. J., Nanoff, C., Strosberg, A. D. and Jockers, R. (1999) Dual signaling of human $\mathrm{Mel}_{1 \mathrm{a}}$ melatonin receptors via $\mathrm{G}_{\mathrm{i} 2}, \mathrm{G}_{\mathrm{i} 3}$, and $\mathrm{G}_{\mathrm{q} / 11}$ proteins. Mol. Endocrinol. 13, 2025-2038.

78 Roy, D. and Belsham, D. D. (2002) Melatonin receptor activation regulates GnRH gene expression and secretion in GT1-7 GnRH neurons: signal transduction mechanisms. J. Biol. Chem. 277, 251-258.

79 Steffens, F., Zhou X.-B., Sausbier, U., Sailer, C., Motejlek, K., Ruth, P., Olcese, J., Korth, M. and Wieland, T. (2003) Melatonin receptor signaling in pregnant and nonpregnant rat uterine myocytes as probed by large conductance $\mathrm{Ca}^{2+}$. activated $\mathrm{K}^{+}$channel activity. Mol. Endocrinol. 17, 21032115.

80 Chan, A. S., Lai, F. P., Lo, R. K., Voyno-Yasenetskaya, T. A., Stanbridge, E. J. and Wong, Y.H. (2002) Melatonin mt1 and MT2 receptors stimulate c-Jun N-terminal kinase via pertussis toxin-sensitive and -insensitive G proteins. Cell Signal. 14, 249-257.

81 Lai, F. P., Mody, S. M., Yung, L. Y., Kam, J. Y., Pang, C. S., Pang, S. F., Wong, Y. H. (2002) Molecular determinants for the differential coupling of $\mathrm{G}_{\alpha 16}$ to the melatonin $\mathrm{MT}_{1}, \mathrm{MT}_{2}$ and Xenopus $\mathrm{Mel}_{1 \mathrm{c}}$ receptors. J. Neurochem. 80, 736-745.

82 Yung, L. Y., Tsim, S. T., Wong, Y. H. (1995) Stimulation of cAMP accumulation by the cloned Xenopus melatonin receptor through $\mathrm{G}_{\mathrm{i}}$ and $\mathrm{G}_{\mathrm{z}}$ proteins. FEBS Lett. 372, 99-102.

83 McArthur, A. J., Hunt, E. A. and Gillette, M. U. (1997) Melatonin action and signal transduction in the rat suprachiasmatic circadian clock: activation of protein kinase $\mathrm{C}$ at dusk and dawn. Endocrinology 138, 627-634

84 Godson, C. and Reppert, S. M. (1997) The $\mathrm{Mel}_{1 \mathrm{a}}$ melatonin receptor is coupled to parallel signal transduction pathways. Endocrinology 138, 397-404.

85 Sharkey, J. and Olcese, J. (2007) Transcriptional inhibition of oxytocin receptor expression in human myometrial cells by melatonin involves protein kinase $\mathrm{C}$ signaling. J. Clin. Endocrinol. Metab. 92, 4015-4019.

86 Nosjean, O., Ferro, M., Cogé, F., Beauverger, P., Henlin, J.M., Lefoulon, F., Fauchère, J.-L., Delagrange, P., Canet, E. and Boutin, J. A. (2000) Identification of the melatoninbinding site MT3 as the quinone reductase 2. J. Biol. Chem. 275, 31311-31317.

87 Nosjean, O., Nicolas, J. P., Klupsch, F., Delagrange, P., Canet, E. and Boutin, J. A. (2001) Comparative parmacological studies of melatonin receptors: MT1, MT2 and MT3/QR2. Tissue distribution of MT3/QR2. Biochem. Pharmacol. 61, $1369-1379$.

88 Mailliet, F., Ferry, G., Vella, F., Berger, S., Cogé, F., Chomarat, P., Mallet, C., Guénin, S. P., Guillaumet, G., Viaud-Massuard, M. C., Yous, S., Delagrange, P. and Boutin, J. A. (2005) Characterization of the melatoninergic $\mathrm{MT}_{3}$ binding site on the NRH:quinone oxidoreductase 2 enzyme. Biochem. Pharmacol. 71, 74-78.

89 Harada, S., Fujii, C., Hayashi, A. and Ohkoshi, N. (2001) An association between idiopathic Parkinson's disease and polymorphisms of phase II detoxification enzymes: glutathione Stransferase M1 and quinone oxidoreductase 1 and 2. Biochem. Biophys. Res. Commun. 288, 887-892.

90 Long, D. J. II, Iskander, K., Gaikwad, A., Arin, M., Roop, D. R., Knox, R., Barrios, R. amd Jaiswal, A. K. (2002) Disruption of dihydronicotinamide riboside:quinone oxidoreductase 2 (NQO2) leads to myeloid hyperplasia of bone marrow and decreased sensitivity to menadione toxicity. J. Biol. Chem. 277, 46131-46139.

91 Hardeland, R., Coto-Montes, A. and Poeggeler, B. (2003) Circadian rhythms, oxidative stress and antioxidative defense mechanisms. Chronobiol. Int. 20, 921-962. 
92 Tan, D.-X., Manchester, L. C., Terron, M. P., Flores, L. J., Tamura, H. and Reiter, R. J. (2007) Melatonin as a naturally occurring co-substrate of quinone reductase-2, the putative $\mathrm{MT}_{3}$ melatonin membrane receptor: hypothesis and significance. J. Pineal Res. 43, 317-320.

93 Benítez-King, G., Huerto-Delgadillo, L. and Antón-Tay, F. (1993) Binding of ${ }^{3} \mathrm{H}$-melatonin to calmodulin. Life Sci. 53, 201-207.

94 Benítez-King, G., Ríos, A., Martínez, A. and Antón-Tay, F. (1996) In vitro inhibition of $\mathrm{Ca}^{2+} /$ calmodulin-dependent kinase II activity by melatonin. Biochim. Biophys. Acta 1290, 191-196.

95 Benítez-King G. (2006) Melatonin as a cytoskeletal modulator: implications for cell physiology and disease. J. Pineal Res. 40, 1-9.

96 Hardeland, R. (1997) New actions of melatonin and their relevance to biometeorology. Int. J. Biometeorol. 41, 47-57.

97 Soto-Vega, E., Meza, I., Ramírez-Rodríguez, G. and BenitezKing, G. (2004) Melatonin stimulates calmodulin phosphorylation by protein kinase C. J. Pineal Res. 37, 98-106.

98 Macías, M., Escames, G., Leon, J., Coto, A., Sbihi, Y., Osuna, A. and Acuña-Castroviejo, D. (2003) Calreticulin - melatonin. An unexpected relationship. Eur. J. Biochem. 270, 832840.

99 Wiesenberg, I., Missbach, M., Kahlen J. P., Schräder, M. and Carlberg, C. (1995) Transcriptional activation of the nuclear receptor RZR $\alpha$ by the pineal gland hormone melatonin and identification of CGP 52608 as a synthetic ligand. Nucleic Acids Res. 23, 327-333.

100 Carlberg, C. (2000) Gene regulation by melatonin. Ann. NY Acad. Sci. 917, 387-396.

101 Tomás-Zapico, C. and Coto-Montes, A. (2005) A proposed mechanism to explain the stimulatory effect of melatonin on antioxidative enzymes. J. Pineal Res. 39, 99-104.

102 Pandi-Perumal, S. R., Srinivasan, V., Maestroni, G. J. M., Cardinali, D. P., Poeggeler, B. and Hardeland, R. (2006) Melatonin: Nature's most versatile biological signal? FEBS J. $273,2813-2838$.

103 Andrabi, S. A., Sayeed, I., Siemen, D., Wolf, G. and Horn, T. F. (2004) Direct inhibition of the mitochondrial permeability transition pore: a possible mechanism responsible for antiapoptotic effects of melatonin. FASEB J. 18, 869-871.

104 Reiter, R. J., Tan, D.-X., Mayo, J. C., Sainz, R. M., Leon, J. and Czarnocki, Z. (2003) Melatonin as an antioxidant: biochemical mechanisms and pathophysiological implications in humans. Acta Biochim. Pol. 50, 1129-1146.

105 Hardeland, R. (2005) Antioxidative protection by melatonin multiplicity of mechanisms from radical detoxification to radical avoidance. Endocrine 27, 119-130.

106 Menendez-Pelaez, A., Poeggeler, B., Reiter, R. J., BarlowWalden, L., Pablos, M. I. and Tan D.-X. (1993) Nuclear localization of melatonin in different mammalian tissues: immunocytochemical and radioimmunoassay evidence. J. Cell. Biochem. 53, 373-382.

107 Mondaca, M., Hernández, A., Valladares, L., Sierralta, W., Noseda, R. and Soto-Moyano, R. (2004) Involvement of melatonin metabolites in the long-term inhibitory effect of the hormone on rat spinal nociceptive transmission. Pharmacol, Biochem. Behav. 77, 275-279.

108 Teh, M. T. and Sugden, D. (2002) Desensitization of pigment granule aggregation in Xenopus leavis melanophores: melatonin degradation rather than receptor down-regulation is responsible. J. Neurochem. 81, 719-727.

109 Ferry, G., Ubeaud, C., Lambert, P. H., Bertin, S., Cogé, F., Chomarat, P., Delagrange, P., Serkiz, B., Bouchet, J. P. Truscott, R. J. and Boutin, J. A. (2005) Molecular evidence that melatonin is enzymatically oxidized in a different manner than tryptophan: investigation on both indoleamine-2,3dioxygenase and myeloperoxidase. Biochem. J. 388, 205-215.

110 Ma, X., Idle, J. R., Krausz, K. W. and Gonzalez, F. J. (2005) Metabolism of melatonin by human cytochromes p450. Drug Metab. Dispos. 33, 489-494.
111 Tricoire, H., Locatelli, A., Chemineau, P. and Malpaux, B. (2002) Melatonin enters the cerebrospinal fluid through the pineal recess. Endocrinology 143, 84-90.

112 Tricoire, H., Møller, M., Chemineau, P. and Malpaux, B. (2003) Origin of cerebrospinal fluid melatonin and possible function in the integration of photoperiod. Reprod. Suppl., $61,311-321$.

113 Ma, X., Idle, J. R., Krausz, K. W., Tan, D.-X., Ceraulo, L. and Gonzalez, F. J. (2006) Urinary metabolites and antioxidant products of exogenous melatonin in the mouse. J. Pineal Res. 40, 343-349.

114 Tan, D.-X., Manchester L. C., Reiter, R. J., Plummer, B. F., Hardies, L. J., Weintraub, S. T., Vijayalaxmi and Shepherd, A. M. (1998) A novel melatonin metabolite, cyclic 3-hydroxymelatonin: a biomarker of in vivo hydroxyl radical generation. Biochem. Biophys. Res. Commun. 253, 614-620.

115 Tan, D.-X., Hardeland, R., Manchester, L. C., Poeggeler, B., Lopez-Burillo, S., Mayo, J. C., Sainz, R. M. and Reiter, R. J. (2003) Mechanistic and comparative studies of melatonin and classic antioxidants in terms of their interactions with the ABTS cation radical. J. Pineal Res. 34, 249-259.

116 Hardeland, R., Poeggeler, B., Niebergall, R. and Zelosko, V. (2003) Oxidation of melatonin by carbonate radicals and chemiluminescence emitted during pyrrole ring cleavage. J. Pineal Res. 34, 17-25.

117 Tan, D.-X., Manchester L. C., Burkhardt, S., Sainz, R. M., Mayo, J. C., Kohen, R., Shohami E, Huo, Y.-S., Hardeland, R. and Reiter, R. J. (2001) $N^{1}$-acetyl- $N^{2}$-formyl-5-methoxykynuramine, a biogenic amine and melatonin metabolite, functions as a potent antioxidant. FASEB J. 15, 2294-2296.

118 Tan, D.-X., Manchester, L. C., Di Mascio, P., Martinez, G. R., Prado, F. M. and Reiter, R. J. (2007) Novel rhythms of $N^{1}$ acetyl- $N^{2}$-formyl-5-methoxykynuramine and its precursor melatonin in water hyacinth: importance for phytoremediation. FASEB J. 21, 1724-1729.

119 Tan, D.-X., Reiter, R. J., Manchester, L. C., Yan, M.-T., ElSawi, M., Sainz, R. M., Mayo, J. C., Kohen, R., Allegra, M. and Hardeland, R. (2002) Chemical and physical properties and potential mechanisms: melatonin as a broad spectrum antioxidant and free radical scavenger. Curr. Top. Med. Chem. 2, 181-197.

120 Agozzino, P., Avellone, G., Bongiorno, D., Ceraulo, L., Filizzola, F., Natoli, M. C., Livrea, M. A. and Tesoriere, L. (2003) Melatonin: structural characterization of its nonenzymatic mono-oxygenate metabolite. J. Pineal Res. 35, $269-275$.

121 Tan, D.-X., Manchester, L. C. Reiter, R. J., Qi, W.-B. Karbownik, M. and Calvo, J. R. (2000) Significance of melatonin in antioxidative defense system: reactions and products. Biol. Signals Recept. 9, 137-159.

122 Seever, K. and Hardeland, R. (2008) Novel pathway for $N^{1}$ acetyl-5-methoxykynuramine: UVB-induced liberation of carbon monoxide from precursor $N^{1}$-acetyl- $N^{2}$-formyl-5-methoxykynuramine. J. Pineal Res., in press.

123 Rosen, J., Than, N. N. Koch, D., Poeggeler, B., Laatsch, H. and Hardeland, R. (2006) Interactions of melatonin and its metabolites with the ABTS cation radical: extension of the radical scavenger cascade and formation of a novel class of oxidation products, C2-substituted 3-indolinones. J. Pineal Res. 41, 374-381.

124 Ressmeyer, A.-R., Mayo, J. C. Zelosko, V., Sáinz, R. M. Tan, D.-X., Poeggeler, B., Antolín, I., Zsizsik, B. K. Reiter, R. J. and Hardeland, R. (2003) Antioxidant properties of the melatonin metabolite $N^{1}$-acetyl-5-methoxykynuramine (AMK): scavenging of free radicals and prevention of protein destruction. Redox Rep. 8, 205-213.

125 Guenther, A.L., Schmidt, S. I., Laatsch, H., Fotso, S., Ness, H., Ressmeyer, A.-R., Poeggeler, B. and Hardeland, R. (2005) Reactions of the melatonin metabolite AMK $\left(N^{1}\right.$ acetyl-5-methoxykynuramine) with reactive nitrogen species: formation of novel compounds, 3-acetamidomethyl-6-methoxycinnolinone and 3-nitro-AMK. J. Pineal Res. 39, 251-260. 
126 Hardeland, R., Backhaus, C. and Fadavi, A. (2007) Reactions of the NO redox forms $\mathrm{NO}^{+}, \cdot \mathrm{NO}$ and $\mathrm{HNO}$ (protonated $\mathrm{NO}^{-}$) with the melatonin metabolite $N^{1}$-acetyl-5-methoxykynuramine (AMK). J. Pineal Res. 43, 382-388.

127 Hardeland, R., Backhaus, C., Fadavi, A. and Hess, M. (2007) $N^{1}$-acetyl-5-methoxykynuramine contrasts with other tryptophan metabolites by a peculiar type of NO scavenging: cyclization to a cinnolinone prevents formation of unstable nitrosamines. J. Pineal Res. 43, 104-105.

128 Tan, D.-X., Chen, L.-D., Poeggeler, B., Manchester, L. C. and Reiter, R. J. (1993) Melatonin: a potent, endogenous hydroxyl radical scavenger. Endocr. J. 1, 57-60.

129 Martín, M., Macías, M., Escames, G., Reiter, R. J., Agapito, M. T., Ortiz, G. G. and Acuña-Castroviejo, D. (2000) Melatonin-induced increased activity of the respiratory chain complexes I and IV can prevent mitochondrial damage induced by ruthenium red in vivo. J. Pineal Res. 28, 242-248.

130 Acuña-Castroviejo, D., Escames, G., León, J., Carazo, A. and Khaldy, H. (2003) Mitochondrial regulation by melatonin and its metabolites. Adv. Exp. Med. Biol. 527, 549-557.

131 Okatani, Y., Wakatsuki, A. and Reiter, R. J. (2002) Melatonin protects hepatic respiratory chain activity in senescenceaccelerated mice. J. Pineal Res. 32, 143-148.

132 Okatani, Y., Wakatsuki, A., Reiter, R. J. and Miyahara, Y. (2002) Hepatic mitochondrial dysfunction in senescence-accelerated mice: correction by long-term, orally administered physiological levels of melatonin. J. Pineal Res. 33, 127-133.

133 Baydas, G., Reiter, R. J., Akbulut, M., Tuzcu, M. and Tamer, S. (2005) Melatonin inhibits neural apoptosis induced by homocysteine in hippocampus of rats via inhibition of cytochrome $\mathrm{c}$ translocation and caspase- 3 activation and by regulating pro- and anti-apoptotic protein levels. Neuroscience $135,879-886$

134 Sourdeval, M., Lemaire, C., Deniaud, A., Taysse, L., Daulon, S., Breton, P., Brenner, C., Boisvieux-Ulrich, E. and Marano, F. (2006) Inhibition of caspase-dependent mitochondrial permeability transition protects airway epithelial cells against mustard-induced apoptosis. Apoptosis 11, 1545-1559.

$135 \mathrm{Xu}, \mathrm{M}$. and Ashraf, M. (2002) Melatonin protection against lethal myocyte injury induced by doxorubicin as reflected by effects on mitochondrial membrane potential. J. Mol. Cell. Cardiol. 34, 75-79.

136 Prada, C., Udin, S. B., Wiechmann, A. F. and Zhdanova, I. V. (2005) Stimulation of melatonin receptors decreases calcium levels in Xenopus tectal cells by activating $\mathrm{GABA}_{C}$ receptors. J. Neurophysiol. 94, 968-978.

137 Prada, C. and Udin, S. B. (2005) Melatonin decreases calcium levels in retinotectal axons of Xenopus laevis by indirect activation of group III metabotropic glutamate receptors Brain Res. 1053, 67-76.

138 Liu, L. Y., Hoffman, G. E., Fei, X. W., Li, Z., Zhang, Z. H. and Mei, Y. A. (2007) Delayed rectifier outward $\mathrm{K}^{+}$current mediates the migration of rat cerebellar granule cells stimulated by melatonin. J. Neurochem. 102, 333-344.

139 Zhang, M., Cao, L. H., Yang, X. L. (2007) Melatonin modulates glycine currents of retinal ganglion cells in rat. Neuroreport 18, 1675-1678.

140 Lardone, P. J., Carrillo-Vico, A., Naranjo, M. C., De Felipe, B., Vallejo, A., Karasek, M. and Guerrero, J. M. (2006) Melatonin synthesized by Jurkat human leukemic T cell line is implicated in IL-2 production. J. Cell Physiol. 206, 273-279.

141 Guerrero, J. M. and Reiter, R. J. (2002) Melatonin-immune system relationships. Curr. Top. Med. Chem. 2, 167-179.

142 Carrillo-Vico, A., Reiter R. J., Lardone, P. J., Herrera, J. L., Fernández-Montesinos, R., Guerrero, J. M. and Pozo, D. (2006) The modulatory role of melatonin on immune responsiveness. Curr. Opin. Invest. Drugs 7, 423-431.

143 García-Mauriño, S., Pozo, D., Carrillo-Vico, A., Calvo, J. R. and Guerrero, J. M. (1999) Melatonin activates Th1 lymphocytes by increasing IL-12 production. Life Sci. 65, 2143-2150.

144 Carrillo-Vico, A., García-Mauriño, S., Calvo, J. R. and Guerrero, J. M. (2003) Melatonin counteracts the inhibitory effect of PGE2 on IL-2 production in human lymphocytes via its $\mathrm{mt} 1$ membrane receptor. FASEB J. 17, 755-757.

145 Lotufo, C. M., Lopes, C., Dubocovich, M. L., Farsky, S. H. and Markus, R. P. (2001) Melatonin and $N$-acetylserotonin inhibit leukocyte rolling and adhesion to rat microcirculation. Eur. J. Pharmacol. 430, 351-357.

146 Markowska, M., Mrozkowiak, A., Pawlak, J. and SkwarłoSońta, K. (2004) Intracellular second messengers involved in melatonin signal transduction in chicken splenocytes in vitro. J. Pineal Res. 37, 207-212.

147 Carrillo-Vico, A., García-Pergañeda, A., Naji, L., Calvo, J. R., Romero, M. P. and Guerrero, J. M. (2003) Expression of membrane and nuclear melatonin receptor mRNA and protein in the mouse immune system. Cell. Mol. Life Sci. 60, 2272-2278.

148 Balzer, I. and Hardeland, R. (1989) Action of kynuramine in a dinoflagellate: stimulation of bioluminescence in Gonyaulax polyedra. Comp. Biochem. Physiol. 94C, 129-132.

149 Kennaway, D. J., Blake, P. and Webb, H. A. (1989) A melatonin agonist and $\mathrm{N}$-acetyl- $\mathrm{N}^{2}$-formyl-5-methoxykynurenamine accelerate the reentrainment of the melatonin rhythm following a phase advance of the light-dark cycle. Brain Res. 495, 349-354.

150 Budu, A., Peres, R., Bueno, V. B., Catalani, L. H. and da Silva Garcia, C. R. (2007) $N^{1}$-acetyl- $N^{2}$-formyl-5-methoxykynuramine modulates the cell cycle of malaria parasites. J. Pineal Res. 42, 261-266.

151 Kelly, R. W., Amato, F. and Seamark, R. F. (1984) N-Acetyl-5methoxy kynurenamine, a brain metabolite of melatonin, is a potent inhibitor of prostaglandin biosynthesis. Biochem. Biophys. Res. Commun. 121, 372-379.

152 Mayo, J. C., Sainz R. M., Tan, D.-X., Hardeland, R., Leon, J., Rodriguez, C. and Reiter, R. J. (2005) Anti-inflammatory actions of melatonin and its metabolites, N1-acetyl-N2formyl-5-methoxykynuramine (AFMK) and N1-acetyl-5-methoxykynuramine (AMK), in macrophages. J. Neuroimmunol. 165, 139-149.

153 Silva, S. O., Ximenes, V. F., Livramento, J. A., Catalani, L. H. and Campa, A. (2005) High concentrations of the melatonin metabolite, $N^{1}$-acetyl- $N^{2}$-formyl-5-methoxykynuramine, in cerebrospinal fluid of patients with meningitis: a possible immunomodulatory mechanism. J. Pineal Res. 39, 302-306.

154 Silva, S. O., Rodrigues, M. R., Ximenes V. F., Bueno-da-Silva, A. E., Amarante-Mendes, G. P. and Campa, A. (2004) Neutrophils as a specific target for melatonin and kynuramines: effects on cytokine release. J. Neuroimmunol. 156, $146-152$.

155 Burkhardt, S., Reiter R. J., Tan, D.-X., Hardeland, R., Cabrera, J. and Karbownik, M. (2001) DNA oxidatively damaged by chromium(III) and $\mathrm{H}_{2} \mathrm{O}_{2}$ is protected by the antioxidants melatonin, $N^{1}$-acetyl- $N^{2}$-formyl-5-methoxykynuramine, resveratrol and uric acid. Int. J. Biochem. Cell Biol. 33, 775-783.

156 Onuki, J., Almeida, E. A., Medeiros, M. H. G. and Di Mascio, P. (2005) Inhibition of 5-aminolevulinic acid-induced DNA damage by melatonin, $N^{1}$-acetyl- $N^{2}$-formyl-5-methoxykynuramine, quercetin or resveratrol. J. Pineal Res. 38, 107-115.

157 Manda, K., Ueno, M. and Anzai, K. (2007) AFMK, a melatonin metabolite, attenuates X-ray-induced oxidative damage to DNA, proteins and lipids in mice. J. Pineal Res. 42, 386-393.

158 León, J., Escames, G., Rodríguez, M. I., López, L. C., Tapias, V., Entrena, A., Camacho, E., Carrión, M. D., Gallo, M. A., Espinosa, A., Tan, D.-X., Reiter, R. J. and Acuña-Castroviejo, D. (2006) Inhibition of neuronal nitric oxide synthase activity by $N^{1}$-acetyl-5-methoxykynuramine, a brain metabolite of melatonin. J. Neurochem. 98, 2023-2033. 